Document downloaded from:

http://hdl.handle.net/10251/104019

This paper must be cited as:

Payri, R.; Viera-Sotillo, JP.; Gopalakrishnan, V.; Szymkowicz, P. (2017). The effect of nozzle geometry over the evaporative spray formation for three different fuels. Fuel. 188:645-660. doi:10.1016/j.fuel.2016.10.064

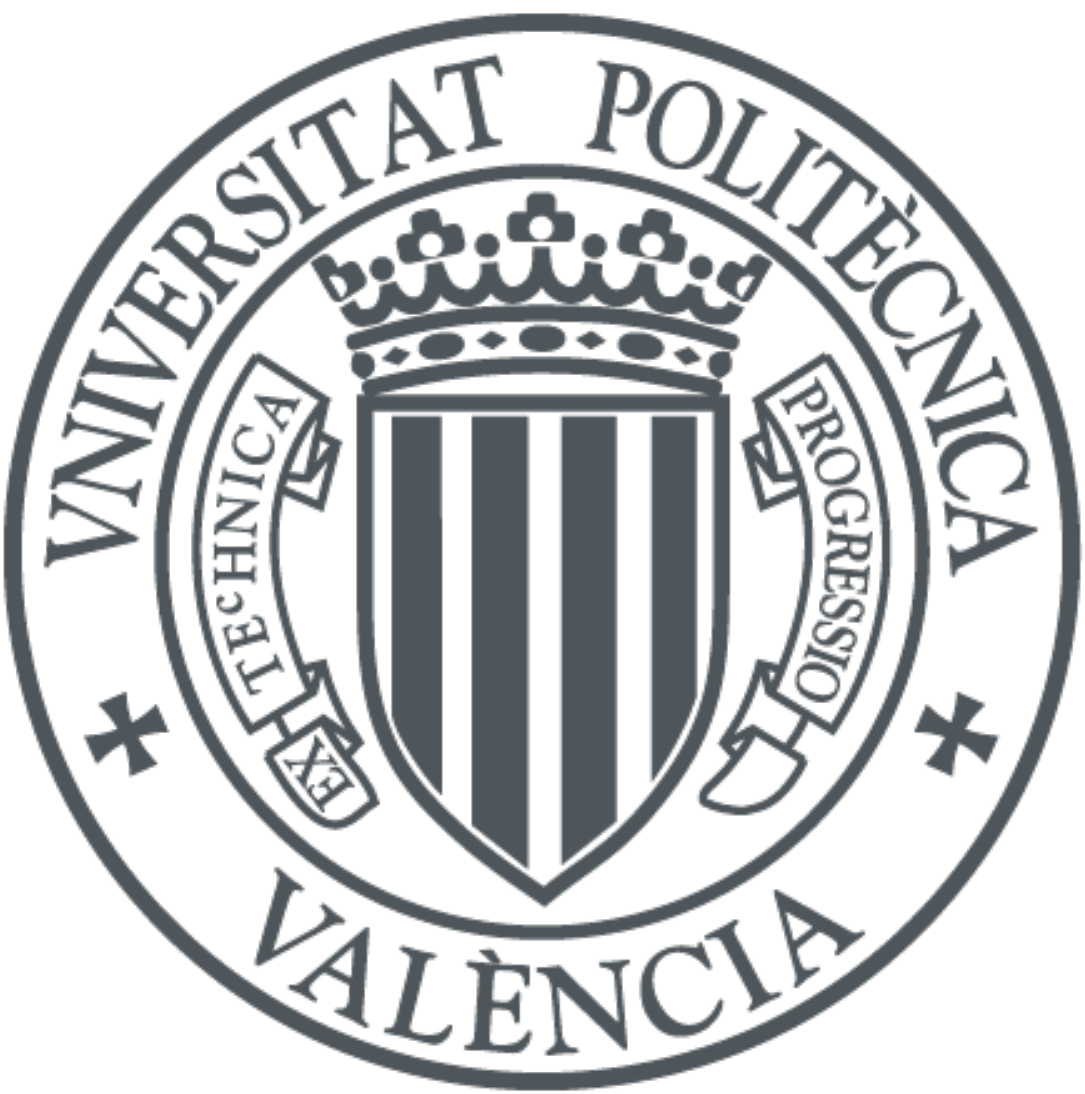

The final publication is available at

http://dx.doi.org/10.1016/j.fuel.2016.10.064

Copyright Elsevier

Additional Information 


\title{
The effect of nozzle geometry over the evaporative spray formation for three different fuels
}

\author{
Raul Payri ${ }^{\mathrm{a}, *}$, Juan P. Viera ${ }^{\mathrm{a}}$, Venkatesh Gopalakrishnan ${ }^{\mathrm{b}}$, Patrick G. \\ Szymkowicz ${ }^{\mathrm{b}}$ \\ ${ }^{a}$ CMT-Motores Térmicos, Universitat Politècnica de Valencia, Camino de Vera s/n, \\ 46022 Valencia, Spain \\ ${ }^{b}$ Diesel Engine Systems Group, Propulsion Systems Research Lab, GM REDD Center, \\ MC: 480-106-252, 30500 Mound Rd., Warren, MI 48090-905, USA
}

\begin{abstract}
1 The influence of internal nozzle flow characteristics over the evaporative spray development is studied experimentally for two different nozzle geometries and three different fuels. This is a continuation of previous work by the authors where non-evaporative isothermal spray development was studied experimentally for the same nozzle geometries and fuels. Current study reports macroscopic spray characteristics by imaging the liquid and vapor phases of the spray simultaneously using independent cameras and optical techniques. The liquid phase is captured by a fast-pulsed diffused back illumination setup, while the vapor phase is captured by a single-pass Schlieren setup with diaphragm. The nozzle geometries consist of a conical nozzle and a cylindrical nozzle with $8.6 \%$ larger outlet diameter when compared to the conical nozzle. Among the three fuels, two are pure components-n-heptane and n-dodecane - while the third consists of a three-component surrogate to better represent the physical and chemical properties of diesel fuel. For a fixed ambient density, the liquid penetration is controlled by ambient temperature while the vapor penetration is controlled by injection pressure. The cylindrical nozzle, in spite of higher mass flow rate and momentum flux,

\footnotetext{
${ }^{*}$ Corresponding author

Email address: rpayri@mot.upv.es (Raul Payri)

${ }^{1}$ Raul Payri, Juan P. Viera, Venkatesh Gopalakrishnan, Patrick G. Szymkowicz,
} The effect of nozzle geometry over the evaporative spray formation for three different fuels, Fuel, Volume 188, 15 January 2017, Pages 645-660, ISSN 0016-2361, http://dx.doi.org/10.1016/j.fuel.2016.10.064.
\end{abstract}


shows slower vapor spray tip penetration when compared to the conical nozzle. Also, the cylindrical nozzle consistently produced shorter liquid lengths. The vapor spray spreading angle is found to be inversely proportional to the spray tip penetration, largely influenced by the nozzle geometry and the ambient density. n-Heptane spray shows the shortest liquid lengths, followed by n-dodecane and finally the Surrogate. No significant difference in vapor penetration rates was found between fuels, confirming that the vapor spray is controlled by momentum, which is independent of fuel. This was not the case for the non-evaporative isothermal sprays previously studied by the authors. Liquid lengths show the expected responses to parametric variations of ambient temperature and density. Two empirical predictive models are presented and utilized to analyze the influence of fuel properties on the liquid length. The primary factor controlling the liquid length between fuels is found to be their volatility. Finally, the cylindrical nozzle exhibits larger lineof-sight contour fluctuations in both the liquid and vapor phases, which in turn contributes to the shorter liquid lengths and slower vapor penetration.

Keywords: Macroscopic spray development, evaporative spray formation, surrogate fuels, liquid length, vapor penetration, spray dispersion

\section{Introduction}

The performance and emissions of direct injection internal combustion engines are significantly controlled by the air-fuel mixture preparation. Fuel injection system technology and capability play key roles in the mixture formation processes [1]. Fuel sprays, being primarily characterized by physically complex phenomena and intrinsically stochastic behavior, are remarkably challenging to comprehend by engine and combustion researchers. Over the last three decades, experimental researchers have studied fuel sprays thoroughly in search for a better understanding of these phenomena and also for supporting data that permits validation of detailed numerical models [2].

Among all challenges presented by the physics of fuel sprays injected in-cylinder, the effect of nozzle geometry on the formation, mixing and combustion of the diesel spray is still of interest to the research community and the automotive industry. Even though it has been studied before, the true extent of the effect of nozzle geometry over a wide span of operating conditions (including fuels) and response variables is not yet fully understood. 


\begin{tabular}{|llll|}
\hline \multicolumn{2}{|l}{ Nomenclature } & & \\
$\rho$ & Ambient density & $P_{r}$ & Rail pressure \\
$\rho_{f}$ & Fuel density & $T_{a}$ & Ambient temperature \\
$\sigma$ & Standard deviation & $T_{b}$ & Boiling temperature \\
$\tau$ & Optical thickness & $T_{f}$ & Fuel temperature at the orifice \\
$\theta$ & Vapor spray spreading angle & $T_{90}$ & Temperature at $90 \%$ evaporation \\
$A$ & Density ratio & $x_{l i q}$ & Predicted liquid length \\
$B$ & Specific energy ratio & $k 0$ & Cylindrical nozzle \\
$C_{a}$ & Area coefficient & $k 15$ & Conical nozzle \\
$C_{p, l i q}$ & Liquid phase constant pressure & CFD & Computational fluid dynamics \\
& specific heat capacity & ECN & Engine Combustion Network \\
$d_{o}$ & Orifice nominal diameter & FOV & Field of view \\
$d_{e f f}$ & Orifice effective diameter & LED & Light-emitting diode \\
$h_{v a p}$ & Specific enthalpy of vaporization & PAH & Polycyclic aromatic hydrocarbon \\
$I$ & Pixel intensity & RMSE & Root-mean-square error \\
$k$ & Proportioning constant & SOI & Start of injection \\
$m$ & Mass fraction & & \\
\hline & & & \\
\hline
\end{tabular}


For instance, Badock et al. [3] and later Ganippa et al. [4] presented results claiming that nozzle flow characteristics have negligible influence over the spray formation and that momentum is the only controlling variable for mixing. Contrasting these studies, several authors show that the flow inside the nozzle influences the near-nozzle region of the spray in terms of liquid-phase break-up, liquid length, and spray angle [5-11]. Many other studies also evidence the effects of nozzle flow characteristics over the macroscopic spray $[6,12-18]$. This contrast, along with the remaining uncertainty on the effect of nozzle geometry on entrainment, combustion, and pollutant formation, leaves room for fundamental questions on the subject.

These fundamental questions could be addressed from the information provided by computational fluid dynamic (CFD) models, which output a large amount of temporal and spatial data that the experimental approach is unable to acquire [2]. The predictive capability of validated CFD models can cut final product costs dramatically. Nevertheless, current stateof-the-art models still require high-fidelity experimental data for validation and accurate bounding of the problem. Majority of current spray models employ initial and boundary conditions at the nozzle exit as an indirect coupling to the flow inside the nozzle $[14,16,17,19]$. Such methods often dampen or lose smaller scale nozzle flow characteristics, and also present numerical issues such as different time-step lengths for each model to be coupled. Hence, the computed spray development using the indirect coupling is mainly dictated by momentum, aerodynamics, and mixing. Recently, a few authors have published computational models that employ a full grid comprising the nozzle internal geometry and the spray [20-25]. It is important to point out that the work presented by Desantes et al. [20, 25] and Xue et al. $[23,24]$ have benefited significantly by the considerable size and good quality of the Engine Combustion Network (ECN) open database and efforts (http://www . sandia.gov/ecn/, [26]), which allowed access to very high resolution tomographies of the internal nozzle geometry, along with extensive experimental data from different institutions around the world. However, the effects of nozzle geometries on spray formation, and to some extent, fuel properties, were still out of the scope of these studies and so these publications do not answer the questions raised about the effects of nozzle flow and fuel characteristics over the macroscopic spray. These type of models could provide significantly more detail to the mechanisms and physics that control the relationship between nozzle flow, cavitation, and spray development, but they still need large amounts of experimental data for validation 
and bounding of the problem.

Fully predictive CFD models demand minimal uncertainties in physical and chemical fuel properties. The development of surrogate fuels is one way to achieve this while providing detailed chemical kinetic mechanisms [2729] further reduced to computable sizes [28, 30] that can be employed in a fully reactive spray model. Surrogate fuels are often carefully tailored to mimic the behavior of real diesel fuel over the diagnostic being performed $[28,31,32]$. For some years, the surrogate of choice for diesel fuel has been a single-component species n-heptane. There have been more than a hundred studies of diesel combustion that have used n-heptane as a convenient surrogate. There have been two important reasons for this choice. First, n-heptane has a Cetane number of 56 that is reasonably close to the Cetane number of common diesel fuel, so its ignition is similar to that of diesel fuel which is convenient for ignition or heat release studies [16, 27, 30, 33, 34]. In addition, a detailed kinetic reaction mechanism for n-heptane was published by Curran et al. [27] in 1998 with all of the detail required to carry out thorough combustion studies. Recently, it has become apparent that n-heptane is not sufficient as a diesel surrogate, for instance, Idicheria and Pickett [35] showed that the n-heptane flame produces considerably less soot than a \#2 diesel flame at similar conditions, and the soot distribution within the flame was also found to be quite different. Therefore, richer surrogates containing aromatics and other species that are important components in diesel fuels must also be represented in the surrogate selected for this study.

Although combustion performance is out of the scope of this publication, different fuels will present different behaviors regarding nozzle flow characteristics. Som et al. [36] presented a study of the effects of fuel properties on cavitation characteristics and nozzle-outlet turbulence kinetic energy, similar to the experimental micro-visualization work presented by Payri et al. [37] and later Jiang et al. [38]. However, neither of these studies show the influences that different cavitation regimes found for each fuel may have on spray formation. Chen et al. [39] presented a study analyzing the effects of diesel and four alternate fuels on droplet diameters, spray penetration and cone angle. However, the effects of cavitation and nozzle flow characteristics are not contrasted with fuels in the paper. On this context, although the link between nozzle flow characteristics and macroscopic spray formation has been partially studied - especially linking the effects of nozzle geometry and cavitation to the spray formation-little to no information is found in the literature regarding the effects of fuel properties on nozzle flow and the cor- 
responding macroscopic spray development, especially combining these with cavitating regimes.

This study is a contribution to the current understanding of the effects of nozzle flow characteristics over the macroscopic evaporative spray development. The study follows up on two previous works which analyze the effect of nozzle geometry on spray formation [40] and the effect of nozzle geometry combined with different fuels on the hydraulic performance and liquid isothermal non-evaporative spray formation [41]. In this work, all experiments were also performed for the same two different nozzle geometries and three fuels. The experimental campaign consisted in visualizing liquid and vapor phases in high temperature/high pressure chamber conditions, covering a reasonable span of parametric variations. With these experiments, two main goals are pursued: first, to evaluate the influence of nozzle flow characteristics over the macroscopic liquid and vapor sprays with supporting experimental data for different fuels and second, an effort is made in obtaining a large database of quality data useful for CFD model validations with different fuels. State-ofthe-art experimental techniques, facilities and equipment were employed in order to ensure highest quality of data acquired and reported.

\section{Materials and methods}

\subsection{Hardware}

\subsubsection{The high temperature and high pressure test rig}

All visualization experiments were performed in a constant pressure-flow test chamber, capable of mimicking the in-cylinder thermo-dynamic conditions of a diesel engine at the time of injection. This test rig features the unique capability of obtaining nearly quiescent and, compared to other facilities such as constant volume chambers [42], steady thermodynamic conditions within the chamber. This is particularly useful for extensive experimental campaigns with parametric variations of thermodynamic test conditions. The quiescent and steady conditions provide a high test repetition rate - also reducing the effective test time for a given set of test conditions - and enhance the shot-to-shot precision of the tests performed.

The high gas temperature is achieved from the heat exchange between the working gas and a set of electrical resistors located inside the inlet pipe that leads to the chamber. The installation is able to produce a maximum ambient temperature and pressure of $1000 \mathrm{~K}$ and $15 \mathrm{MPa}$ respectively, in the test chamber. The chamber has three large optical accesses $-128 \mathrm{~mm}$ in 
diameter - placed orthogonally in order to have complete optical access to the injection event. A description, photo and schematic of the installation can be found in works previously published by the authors $[43,44]$.

\subsubsection{The fuel injection system}

A common-rail injection system consisting of a high pressure pump and a conventional rail with an electronic pressure regulator is used [45]. This system can generate relatively high rail pressures of up to $220 \mathrm{MPa}$ and maintain it at the set value while injecting fuel. The injector body temperature is controlled using a special injector holder designed to have coolant flowing in direct contact with the injector body. The temperature of the coolant is adjusted in function of the discharge chamber gas temperature and density, to guarantee a constant sac inner wall temperature of approximately $110^{\circ} \mathrm{C}[46]$. The injector's return line is pressurized to $0.6 \mathrm{MPa}$ as required by the injection system to work properly. The entire fuel injection system is electronically controlled and all the settings are introduced digitally.

\subsubsection{Nozzles}

All experiments are performed for two different nozzles, mounted on two independent injector bodies. Table 1 summarizes the injectors utilized and their nominal nozzle geometries. The injectors are piezo-electrically actuaded. The two nozzles are micro-sac type single-hole nozzles, with different conicity but equal hydro grinding (13.5\% each) and nominal flow rate $\left(124 \mathrm{~cm}^{3} / \mathrm{min} / 10 \mathrm{MPa}\right.$ each). Note that Table 1 includes reference symbol and color columns which indicate the symbols and/or colors that will be used to distinguish nozzles in the results section.

Table 1: Injector hardware utilized and nominal nozzle geometries.

\begin{tabular}{cccccc}
\hline Nozzle ref. & Nozz. type & Do $[\mu m]$ & k-factor & Ref. symbol & Ref. color \\
\hline k0 & micro-sac & 151 & 0 & $\diamond$ & purple \\
k15 & micro-sac & 138 & 1.5 & $\circ$ & green \\
\hline
\end{tabular}

\subsubsection{Fuels}

All experiments were also performed for three different fuels. The first fuel selected is n-heptane. As stated in the Introduction section, n-heptane has long been utilized as a diesel surrogate to mimic diesel fuels in ignition and/or 
heat release studies $[27,30,33,34]$. The second fuel selected is n-dodecane, which features similar carbon content and boiling characteristics to those of diesel fuels, so it is expected to better mimic the mixing behavior of diesel fuels. This is one of the reasons n-dodecane was also selected as the primary fuel of study for the main ECN campaign [26], and it has been extensively characterized in the complete spectrum of experimental diagnostics and numerical simulations performed by the group. However, n-dodecane is not expected to be an adequate surrogate for ignition-related behavior, because of its Cetane number (approx. 88). Last, a multi-component diesel surrogate consisting of n-tetradecane (0.5), n-decane (0.25) and $\alpha$-methylnaphthalene (0.25) is utilized. Numbers in parentheses represent mass fractions. This surrogate - from this point foward simply referred to as "Surrogate" - is expected to better mimic the soot-related behavior of real diesel fuel due to the $\mathrm{PAH}$ content and $\mathrm{C} / \mathrm{H}$ ratio being closer to that of real diesel fuel. The short ignition delays expected due to the large n-tetradecane and n-decane contents (with Cetane numbers close to 96 and 77 respectively) are, at the same time, delayed by the the $\alpha$-methylnaphthalene content. Nevertheless, combustion behavior is out of the scope of this publication, so only the fuel properties relevant to this study are summarized in Table 2.

Table 2: Fuels utilized and their properties at $298 \mathrm{~K}$ and $101 \mathrm{kPa}$. Except for the Surrogate fuel, all properties were extracted from the NIST Chemistry WebBook [47]. For the Surrogate fuel, density, viscosity and surface tension were measured as per ASTM D1298, ASTM D445 and UNE EN 14370 respectively.

\begin{tabular}{lcccc}
\hline Property & Units & n-Heptane & n-Dodecane & Surrogate \\
\hline Density & $\mathrm{kg} / \mathrm{m}^{3}$ & 679.7 & 745.8 & 802.1 \\
Viscosity & $\mathrm{Pas}$ & $5.59 \mathrm{e}-4$ & $1.36 \mathrm{e}-3$ & $1.61 \mathrm{e}-3$ \\
Surface tension & $\mathrm{N} / \mathrm{m}$ & 0.020 & 0.025 & 0.026 \\
Boiling point & $\mathrm{K}$ & 372 & 489 & 450 to 520 \\
$C_{p, l i q}$ & $\mathrm{~J} / \mathrm{kg} / \mathrm{K}$ & 2234 & 2212 & Tab. 3 \\
$h_{\text {vap }}$ & $\mathrm{kJ} / \mathrm{kg}$ & 359 & 358 & Tab. 3 \\
\hline Ref. color & - & cyan & blue & magenta \\
\hline
\end{tabular}

The Surrogate distillation curve is presented in Figure 1. This Surrogate starts boiling near $450 \mathrm{~K}$, the boiling point of n-decane. On the other hand, it is completely evaporated near $520 \mathrm{~K}$, the boiling point of n-tetradecane, which comprises half of the mass of the Surrogate fuel. Note also that n- 
Table 3: Components of the Surrogate fuel and their properties at $298 \mathrm{~K}$ and $101 \mathrm{kPa}$. All properties were extracted from the NIST Chemistry WebBook [47].

\begin{tabular}{lcccc}
\hline Property & Units & n-Tetradecane & n-Decane & $\alpha$-methylnaphthalene \\
\hline Boiling point & $\mathrm{K}$ & 523 & 447 & 515 \\
$C_{p, l i q}$ & $\mathrm{~J} / \mathrm{kg} / \mathrm{K}$ & 2208 & 2192 & 1578 \\
$h_{\text {vap }}$ & $\mathrm{kJ} / \mathrm{kg}$ & 361 & 361 & 415 \\
\hline
\end{tabular}

heptane features a boiling point considerably lower than the boiling range of the Surrogate, which at the same time includes the boiling point of ndodecane. From these properties, it would be expected for n-heptane to feature much shorter liquid penetration lengths in comparison to the other two fuels, with the Surrogate fuel showing the longest values.

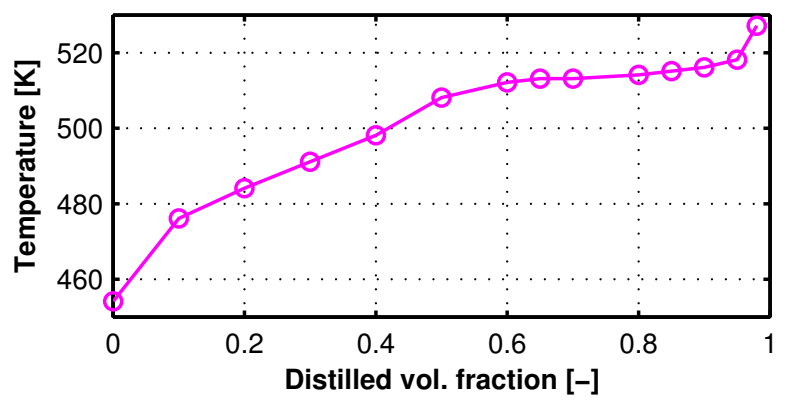

Figure 1: Distillation curve for the Surrogate fuel as per ASTM D86.

\subsection{Evaporative inert spray visualization}

\subsubsection{Optical setup}

The optical setup, shown in Figure 2, consisted of two separate cameras and optical arrangements for the visualization of liquid and vapor phases of the fuel spray. Note that even though the cameras' frame rates were not equal, both cameras recorded all injection events simultaneously.

Liquid phase was visualized through a diffused back illumination (DBI) setup. The recent introduction of a high speed pulsed light-emitting diode (LED) has made this optical setup/technique very convenient for liquid spray visualization of single hole nozzles [40, 41, 48, 49]. Current high-speed camera capabilities in combination with a high-speed pulsed light source - with a controlled pulsed duration of $50 \mathrm{~ns}$ - produce images significantly sharper 
than any continuous light source or flash type light source option, and reduce the actual timing uncertainties of the image acquired. In this setup, the light emitted by the source is forced through a diffuser, a field lens and a beam splitter before going into the chamber. Inside the chamber, the light passes through the liquid core with refractive index much greater than the surrounding gas. This difference in refractive indices deflects light strongly such that the beams entering the liquid core are not captured by the camera which, in turn, renders dark spots on the image at those corresponding locations. The main trajectory of this light is indicated by the blue arrow in Figure 2. Note that since the source light is diffuse, each pixel rendered in the image results from a composition of beams that take different paths through the test chamber, hence, the collection system captures all but highly deflected rays (i.e. those that cross liquid phase), which makes this technique virtually insensitive to small refractive index changes such as local gas temperature fluctuations or the vapor phase of the fuel spray. This is translated into a diffuse, constant and smooth background which is essential for the pixel-wise extinction computation explained later in the image processing section [48, 49]. A slight effect of the vapor phase is still observable in the instantaneous images (often referred to as "beam steering" [48]) but this is discarded by feeding the segmentation algorithm with the appropriate threshold $[48,50]$. The camera utilized for this technique was a Phantom V12, acquiring images of 320 pix $\times 96$ pix at $120 \mathrm{kHz}$ with a spatial resolution of $6.38 \mathrm{pix} / \mathrm{mm}$. This produced a $50 \mathrm{~mm}$ field of view (FOV) along the spray axis, and a maximum measurable penetration length of $45 \mathrm{~mm}$, taking into account the location of the nozzle. The actual exposure time was given by the effective LED pulse duration, which was set to $50 \mathrm{~ns}$.

Schlieren imaging has been successfully employed by several researchers to identify gradients in refractive indices of transparent media. For vaporizing diesel sprays, this technique is able to capture the line-of-sight boundary between vaporized fuel and ambient gases, as there is an appreciable difference in refractive indices between these $[2,26,50]$. Since the rays of light are collimated into a cylindrical beam, small deflections due to refractive index gradients are rendered in the image as shades. In this study, the vapor spray was visualized through a single-pass Schlieren setup [2], which is often applied to axi-symmetrical single hole nozzles. Multi-hole injectors require a two-pass setup and a high temperature mirror as explained by Payri et al. [43]. The final setup is very similar to the setups employed for the CMT experiments in $[26,44,51]$. The camera was a Photron SA5, sampling images 


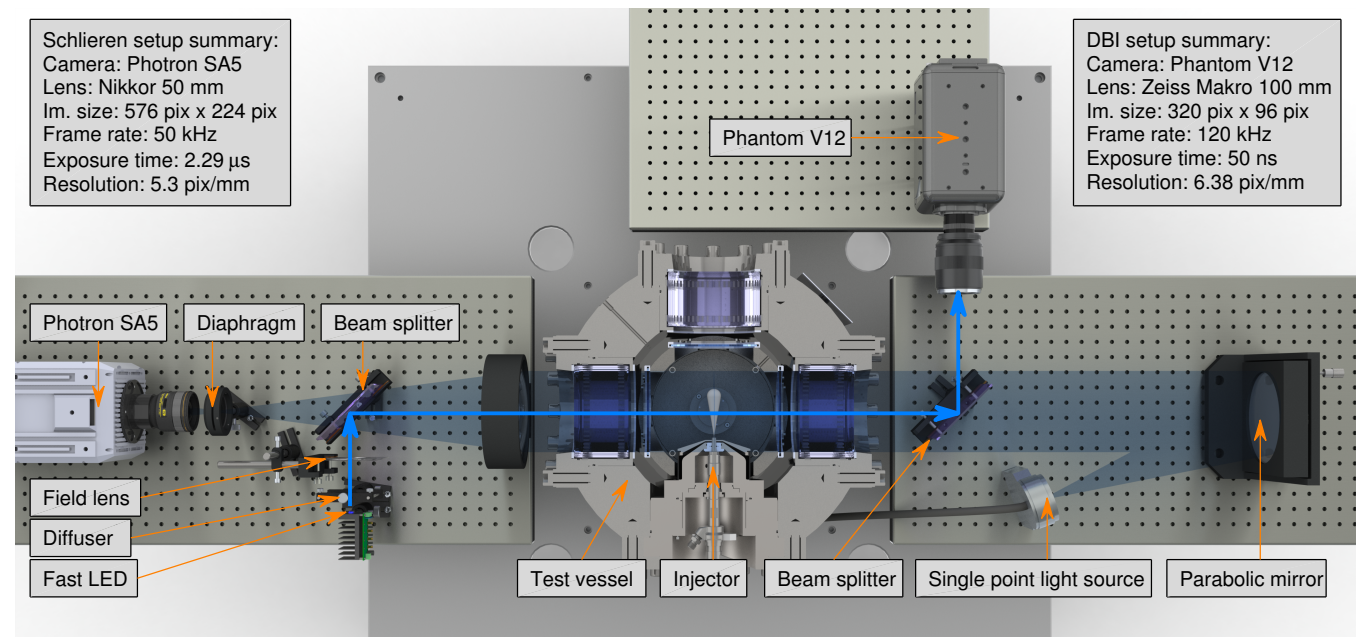

Figure 2: Plan view of the optical setup.

of 576 pix $\times 224$ pix at $50 \mathrm{kHz}$ with a spatial resolution of $5.3 \mathrm{pix} / \mathrm{mm}$. This produced a field of view (FOV) along the spray axis of $108 \mathrm{~mm}$, and considering window limits and nozzle location, the maximum penetration length measurable was $96 \mathrm{~mm}$. The exposure time was set to $2.28 \mu \mathrm{s}$.

As shown in Figure 2, beam splitters were located at either side of the vessel to allow for the light of each technique to travel across the same lineof-sight but in different directions.

\subsubsection{Image processing}

Each image is processed using an algorithm that detects the spray boundary and computes its associated properties. The algorithms varied between the two techniques to maximize the detection performance of each setup.

Diffused back illumination (DBI) images were processed with a segmentation algorithm that binarizes a pre-processed image based on absolute threshold. The pre-processed image is a 2D extinction map, obtained by computing the pixel-wise optical thickness $(\tau)$ following Beer-Lambert's law:

$$
\tau=-\ln \left(I_{i} / I_{o}\right)
$$

Where $I_{i}$ is the digital value of a given pixel at instant $i$ and $I_{o}$ is the digital value of that same pixel in the reference state, which, in this case is the background image before the injection. The background is calculated as an 
ensemble average of all the images acquired before start of injection (SOI). The absolute threshold set for the binarization of the resulting extinction map computed from Eq. (1) was set to $0.6[48,50]$.

Schlieren images are processed differently. The program consists of two extensively used approaches for the processing of these type of images. Two binarized images are obtained from two different criteria and then merged to maximize sensitivity. The first algorithm was originally developed at Sandia National Laboratories (SNL) and is available for download on the ECN website (http://www. sandia.gov/ecn/). The routine detects temporal changes in pixel-wise intensities by taking the temporal derivative of a series of images. This produces a 2D map where pixels with higher intensity represent pixels that are changing their digital values in time. The temporal nature of this algorithm makes it robust to variations between optical setups, and makes it very strong for transparent spray images, for example, of very dilute sprays, low ambient density conditions, light fuels, etc. On the other hand, it does not work properly for spray images with relatively constant intensity levels, for example: images of non-evaporative sprays, diaphragm-cut Schlieren vapor sprays (which are often very dark), combustion-saturated sprays, etc. In these situations, spray tip penetration is still captured correctly while the full spray boundary is not. Therefore, an additional intensity-sensitive algorithm was adapted, explained in detail by Payri et al. [43], enhanced with the dynamic background correction detailed by Benajes et al. [51] and Payri et al. [44]. The two binary maps obtained from each algorithm are combined into a single binary image from which the contour is extracted. This approach maximizes sensitivity since it takes advantage of the robustness of the SNL algorithm for the spray tip region - and dilute regions or sprays - but at the same time allows for good contour detection in the near nozzle region, where the liquid core often generates a very dark image.

All processing algorithms extract macroscopic characteristics from the detected contours. Figure 3 illustrates the definitions for the spray tip penetration and spreading angle utilized in this study. The penetration is calculated as the distance between the outlet orifice and the furthest point in the detected boundary. The spreading angle is calculated as the angle included between two lines that originate at the outlet orifice and are fitted to the spray contours detected within $3.6 \mathrm{~mm}$ and $15 \mathrm{~mm}$ axially measured from the nozzle tip. 


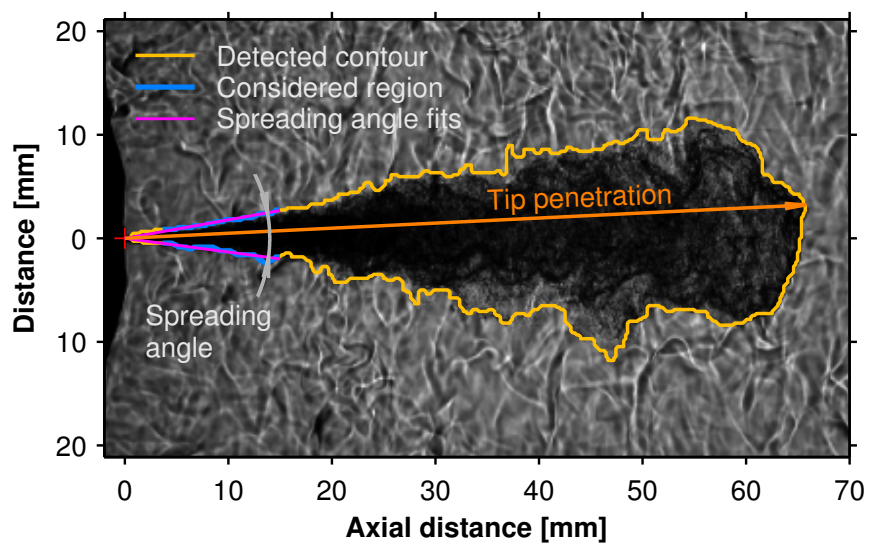

Figure 3: Spray tip penetration and spreading angle definitions illustrated over a Schlieren image of nozzle $k 0$, injecting the Surrogate fuel at $150 \mathrm{MPa}$, with an ambient temperature of $900 \mathrm{~K}$ and an ambient density of $22.8 \mathrm{~kg} / \mathrm{m}^{3}$.

Table 4: Spray visualization test plan, centered on ECN Spray A boundary conditions [26].

\begin{tabular}{lll}
\hline Parameter & Value-Type & Units \\
\hline Ambient density & 22.8 & $\mathrm{~kg} / \mathrm{m}^{3}$ \\
Ambient temperature & $800,900,970$ & $\mathrm{~K}$ \\
Rail pressure & $60,90,150,200$ & $\mathrm{MPa}$ \\
Number of points & 12 per nozzle and fuel & \\
\hline Ambient density & $15.2,30.4$ & $\mathrm{~kg} / \mathrm{m}^{3}$ \\
Ambient temperature & 800,900 & $\mathrm{~K}$ \\
Rail pressure & $60,90,150$ & $\mathrm{MPa}$ \\
Number of points & 12 per nozzle and fuel & \\
\hline Total number of points & 24 per nozzle and fuel & \\
\hline
\end{tabular}




\subsubsection{Test plan}

The test plan is presented in Table 4, it is centered on ECN Spray A boundary conditions [26], with parametric variations around these. Since the time available for experiments was limited, an additional rail pressure $(200 \mathrm{MPa})$ and ambient temperature $(970 \mathrm{~K})$ were performed only at the reference ambient density case $\left(22.8 \mathrm{~kg} / \mathrm{m}^{3}\right)$. Table 4 is sub-divided into these two groups of points for easier visualization of the test plan. For all conditions, the vessel was filled with nitrogen and the energizing time was fixed at $2.5 \mathrm{~ms}$. All test points were performed for the two nozzles and three fuels, comprising a total of 144 test points in the high temperature/high pressure test rig. Note that all experimental results presented in this manuscript are available for download at: http://www.cmt.upv.es/DD01.aspx.

\section{Results}

\subsection{Evaporative spray development}

Figure 4 presents a time sequence of Schlieren images of two independent injection events. This sequence demonstrates the typical behavior of evaporative diesel sprays: fuel is injected into a hot ambient gas, the jet velocity and ambient density shear and atomize the liquid core, the spray entrains the surrounding hot gas which transfers energy to the liquid fuel and, downstream, liquid fuel eventually evaporates completely [52]. The vapor phase continues to penetrate, exchanging momentum with the ambient gas and progressively slowing down. Note how the liquid core of n-heptane spray is considerably smaller than the Surrogate spray, not only in the axial direction but also in width. The vapor phase of the two fuels, however, present very similar behavior in terms of spray tip penetration and angle. These findings will be analyzed in detail in the following sections.

\subsection{Spray tip penetration}

This section presents spray tip penetration results. Each curve in figures presented in this section depicts the spray penetration as a function of time obtained by ensemble averaging multiple consecutive injection events, following the same rolling-average algorithm described by Payri et al. [43], utilizing a window size of $200 \mu \mathrm{s}$. The algorithm is very similar to an Savitzky-Golay digital filter but accounting for multiple digital signals (the multiple test repetitions performed). 

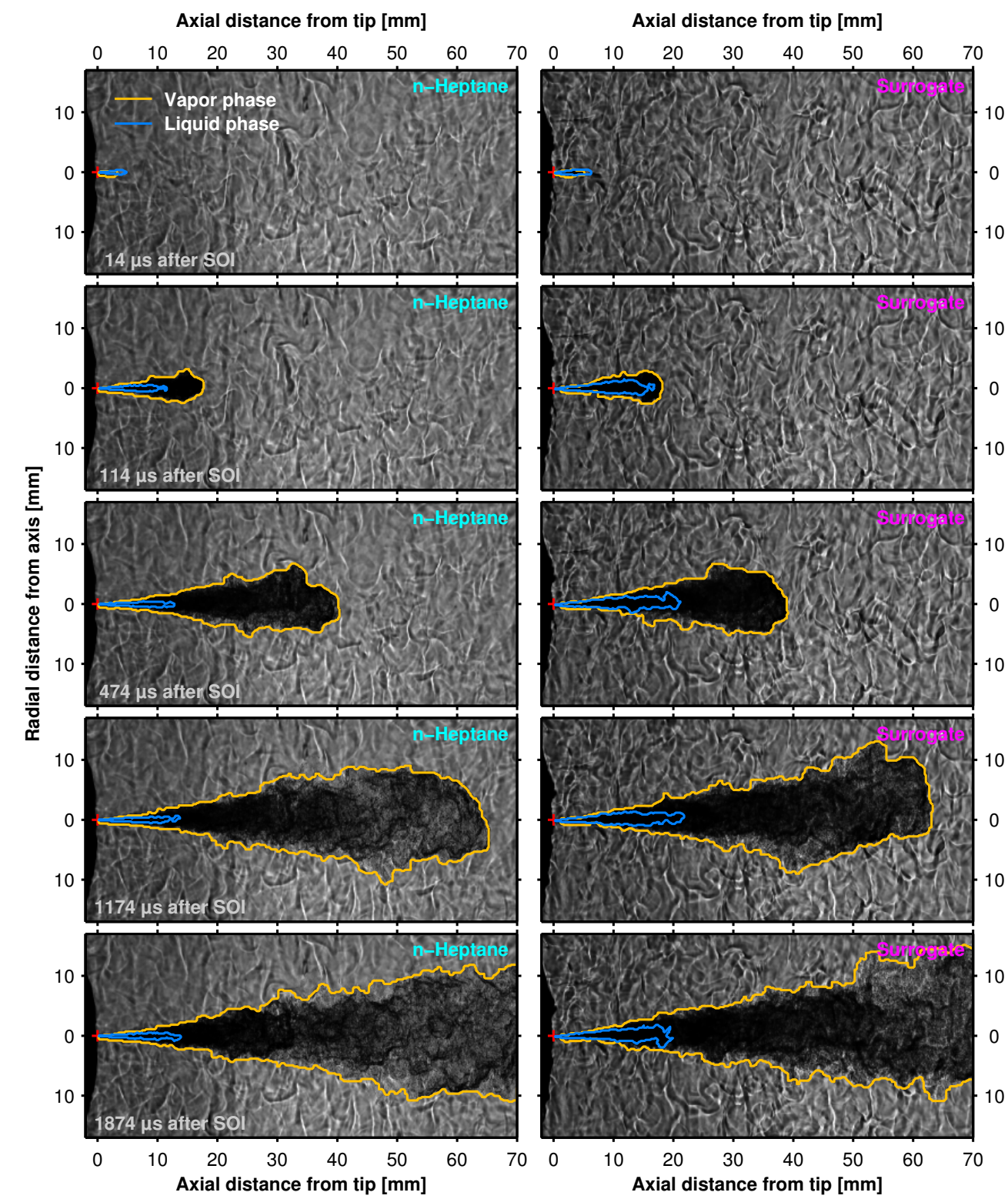

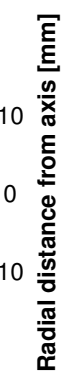
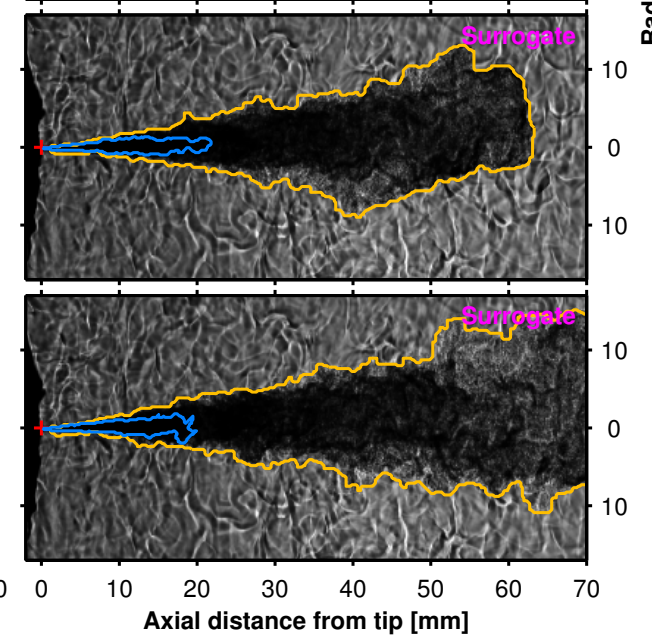

Figure 4: Time sequence of Schlieren images of two injection events. Images have been trimmed both in the radial and axial directions from their original size, for better fit in this figure. The contours detected for the liquid and vapor phases are plotted to scale over the original Schlieren images. Note that contours detected for the liquid phase come from DBI images acquired with the other camera. In this case, the nozzle is $k 15$, rail pressure is $150 \mathrm{MPa}$, ambient density is $22.8 \mathrm{~kg} / \mathrm{m}^{3}$ and ambient temperature is $800 \mathrm{~K}$ 
The ensemble-averaged signal is then aligned in time with the SOI timing, which is estimated by performing a linear fit to the raw data set found in the first $7 \mathrm{~mm}$ of the penetration curves of all repetitions, for a given set of test conditions. A good estimation of the actual SOI for each test condition facilitates the time-phasing of the penetration curves for comparison. In this section, continuous and dashed curves represent the vapor and liquid phases of the spray, respectively, unless specified otherwise.

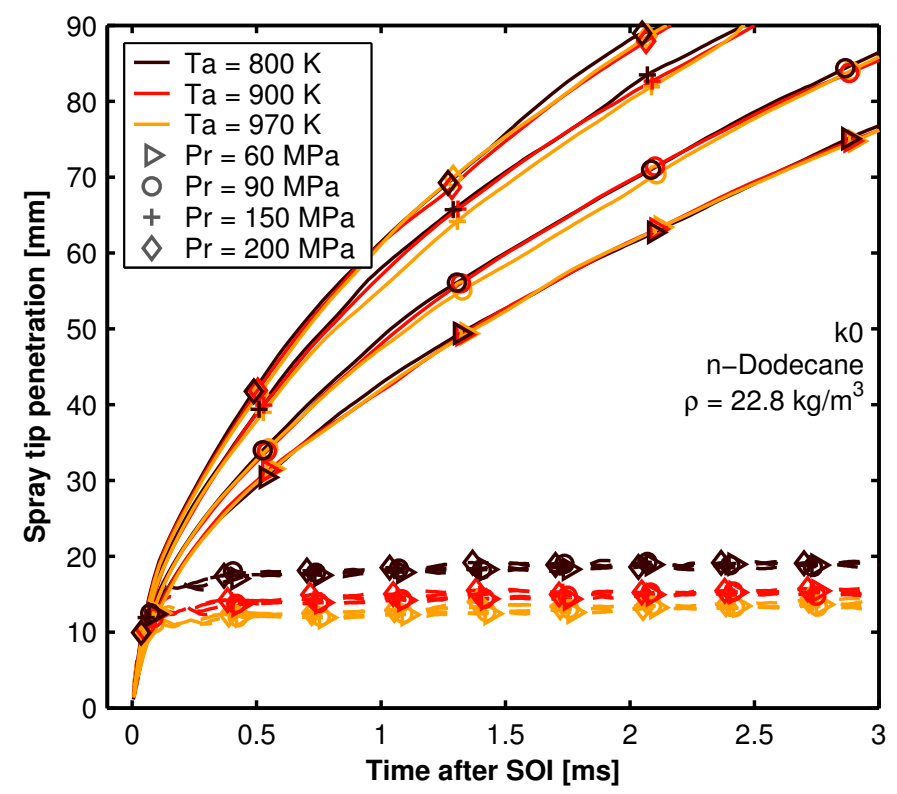

Figure 5: The effect of ambient temperature on the vapor and liquid spray development. In this case, the nozzle is $k 0$, the fuel presented is n-dodecane and ambient density is $22.8 \mathrm{~kg} / \mathrm{m}^{3}$.

\subsubsection{The effect of ambient temperature and rail pressure}

Ambient density $(\rho)$, ambient temperature $\left(T_{a}\right)$ and rail/injection pressure $\left(P_{r}\right)$ are few of the most important parameters, when considering evaporating diesel sprays, that significantly influence the spray and combustion behavior [35, 44]. Ambient density and rail/injection pressure act as a momentum sink and source, respectively while ambient temperature serves as evaporative energy source. Figure 5 presents a particular case of nozzle $k 0$ injecting $n$-dodecane fuel at four different rail pressures and three different 
ambient temperatures. The ambient density is fixed at $22.8 \mathrm{~kg} / \mathrm{m}^{3}$ by increasing the ambient pressure $\left(P_{a}\right)$ from $5.53 \mathrm{MPa}$ to $6.72 \mathrm{MPa}$ compensating for increase in $T_{a}$ from $800 \mathrm{~K}$ to $970 \mathrm{~K}$, respectively. For a fixed ambient density (momentum sink), the liquid penetration curves (dashed lines) collapse by ambient temperature values while the vapor penetration curves (solid lines) collapse by injection pressure values. Thus the liquid penetration is controlled by ambient temperature (evaporative energy source to vaporize fuel), while the vapor penetration is controlled by injection pressure (momentum source). The liquid penetration length is not influenced by rail pressure. This is typical when there is abundance of evaporative energy available, i.e., the rate of vaporization is influenced by rate of entrainment/mixing. As the fuel injection rate increases with injection pressure, the air entrainment increases proportionately, thus maintaining the energy balance and liquid length as previously observed in literature [52, 53]. Since the vapor spray is momentum-driven, changes in ambient temperature - at constant ambient density - are not expected to affect the vapor spray penetration or spreading angle, as the authors have previously observed $[54,55]$. There is a secondary effect due to increase in $P_{a}$ and $T_{a}$ to maintain constant $\rho$, the momentum flux of the spray decreases and hence, the vapor penetration decreases. However, it is not experimentally observable as a clear trend as the variation of $P_{a}$ is much less $(<1.6 \%)$ than $P_{r}$.

\subsubsection{Comparing nozzles}

Figure 6 shows a subset of the full test matrix results obtained from the experiments. The effect of injection pressure (top), and ambient density (bottom) on spray development are shown for the two different nozzles. The different test conditions are indicated by symbols.

Overall, in spite of lower mass flow rate and momentum flux [41], the conical nozzle $k 15$ shows faster tip penetration rates in the later stages of the spray development (time $>0.5 \mathrm{~ms}$ ) when compared to the cylindrical nozzle $k 0$. This occurs because of the turbulent velocity profiles produced by the cylindrical nozzle [56], that enhance spray mixing and momentum exchange which in turn leads to slower tip penetration. Therefore, at higher rail pressures (Figure 6-top), where the effect of aerodynamic drag loses importance, the difference in the penetration of sprays produced by the two nozzles is reduced. This is also due to the increasingly higher momentum flux from nozzle $k 0$ at higher rail pressures in comparison to nozzle $k 15$ [41]. Consequently, the low injection pressure case shown in the bottom part of Figure 

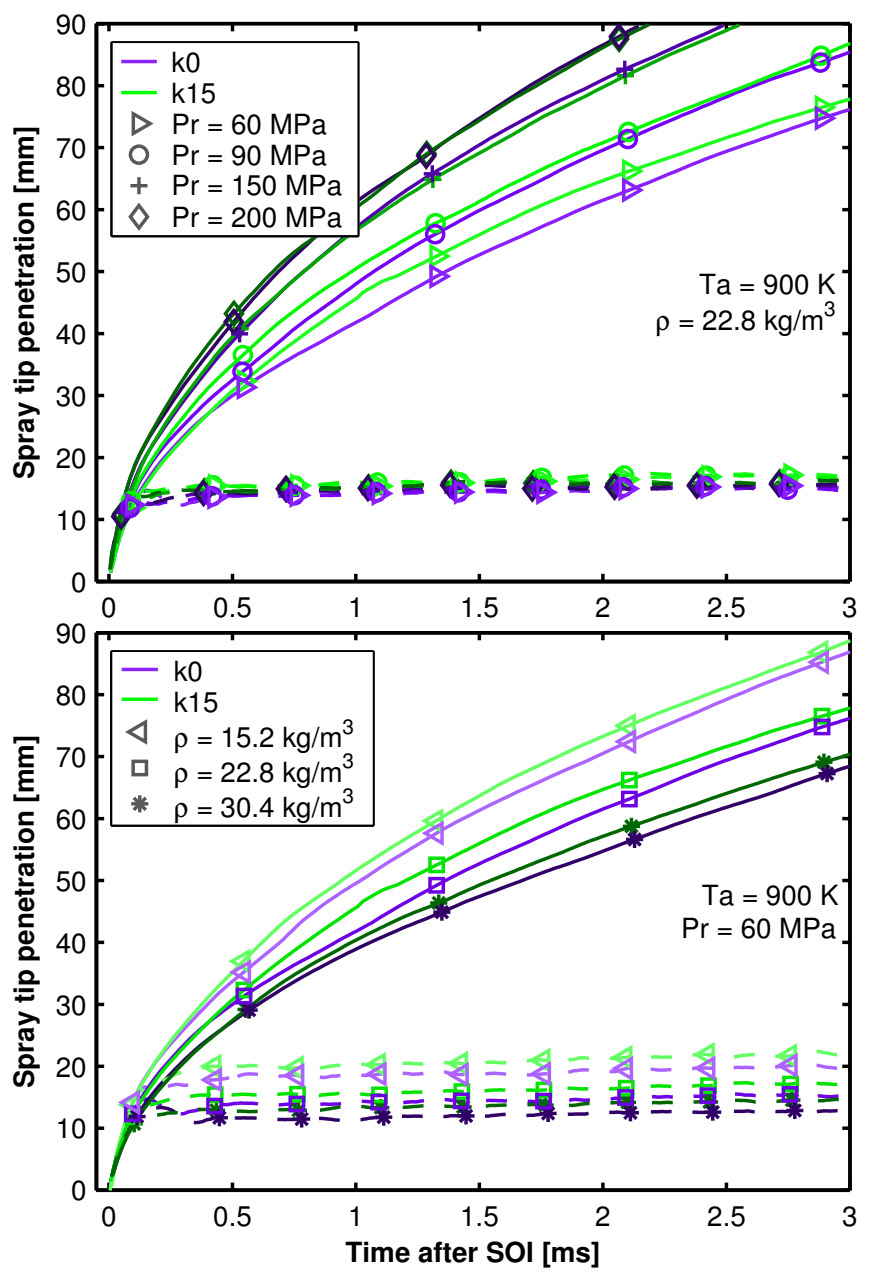

Figure 6: The effect of nozzle geometry on spray tip penetration for different rail pressures at an ambient density of $22.8 \mathrm{~kg} / \mathrm{m}^{3}$ (top), and different ambient densities at a rail pressure of $60.0 \mathrm{MPa}$ (bottom). In this case, the fuel presented is n-dodecane and the ambient temperature is $900 \mathrm{~K}$. 
6 for all densities, marks a clear difference between the penetration rate of the two nozzles, with $k 15$ being consistently the faster of the two. These conditions allow time for the aerodynamic interactions to develop, and turbulent velocity profiles in the outlet orifice become more important to the gas entrainment process. The higher turbulence at the outlet of the cylindrical orifice $k 0$ enhances liquid phase break-up, smaller droplets evaporate faster and exchange momentum more efficiently with the ambient gas which reduces the liquid length in the stabilized region. For the vapor phase, the turbulence is carried over, enhancing momentum exchange and thus slowing down the spray in comparison to the conical nozzle.

The authors already reported similar behavior from comparable experiments and conditions for isothermal non-evaporative sprays of the same nozzles and fuels $[40,41]$. The trends presented in those studies were similar to those presented in this paper for the vapor phase, not only directly comparing nozzles, but also in how the nozzles responded to ambient density and rail pressure. Similar results - comparing nozzles in both liquid and vapor phase sprays - were also reported previously by Som et al. [16] and Montanaro et al. [17]. In both studies, authors perform numerical simulations of isothermal and evaporative sprays for cylindrical and conical nozzles, showing that the penetration curves start to diverge after a certain time has passed and aerodynamic interaction has played its part, even though the effect of nozzle geometry is just introduced as boundary conditions at the orifice interface. Note that Montanaro et al. [17] observed the same trend in their experimental results, presented in the same paper but discussed in detailed further by Zhang et al. [18].

In the case of the vapor spray, the comparison between nozzles was similar for all fuels. This was not the case for the isothermal non-evaporative sprays studied previously by the authors [41], which suggests that the vapor spray penetration is mainly controlled by momentum and therefore, independent of fuel. This is discussed in detailed in the next section.

Figure 6 also shows the behavior of the liquid phase penetration (dashed lines). The cylindrical nozzle $k 0$ consistently showed shorter stabilized liquid penetration lengths when compared to the conical nozzle $k 15$, throughout the full test matrix. This is attributed to the increased turbulence at the outlet orifice and the consequent larger near-field spreading angle [40, 41]. Figure 6 also illustrates, once more, how the stabilized liquid lengths are independent of injection pressures but strongly affected by and inversely proportional to ambient density [52]. 


\subsubsection{Comparing fuels}
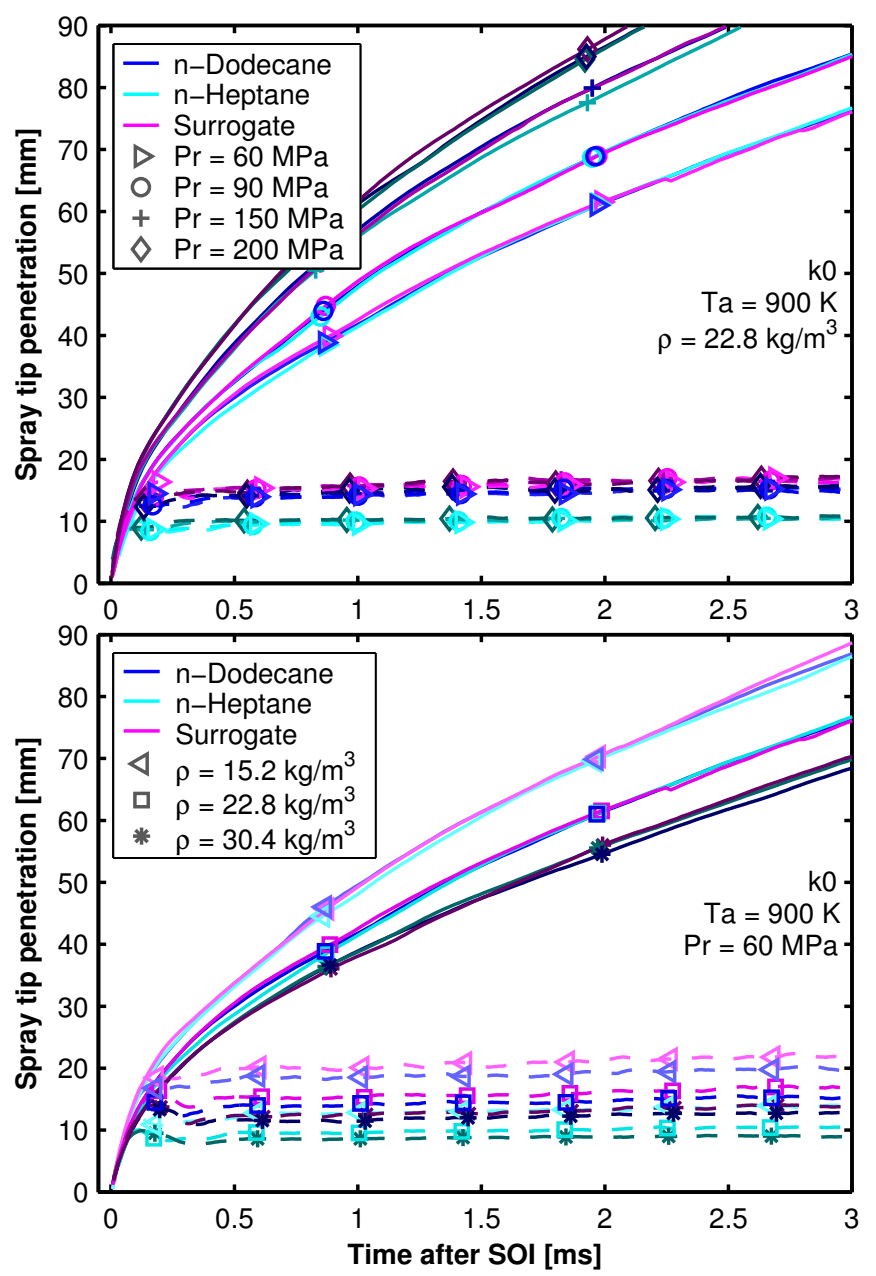

Figure 7: Spray tip penetration for all fuels and different rail pressures at an ambient density of $22.8 \mathrm{~kg} / \mathrm{m}^{3}$ (top), and different ambient densities at a rail pressure of $60.0 \mathrm{MPa}$ (bottom). In this case, the nozzle is $k 0$ and the ambient temperature is $900 \mathrm{~K}$.

A similar analysis can be carried out comparing fuels. Figure 7 presents results of the evolution of the spray tip penetration for select test conditions. Overall, the vapor spray tip penetrations observed were similar for all fuels. This is in agreement with the observations of the nozzle comparisons, where both nozzles responded in similar ways to different fuels. This is also in agreement with the observations of Kook and Pickett [57], and confirms that 
the vapor spray tip penetration is independent of the fuel utilized, keeping the rest of the variables constant, since spray momentum is also independent of fuel [41, 57], even though the rate of injection is affected by fuel density $[41,58]$. The top part of Figure 7 confirms, once again, how the liquid length is independent of injection pressure, while the bottom part of Figure 7 shows the liquid lengths inversely proportional to ambient density, as expected [52].

Regarding fuels, n-heptane showed the shortest liquid lengths, followed by n-dodecane, with the Surrogate fuel consistently featuring longer liquid lengths. The stabilized liquid length is determined by the axial location at which the liquid spray has entrained the necessary energy to fully evaporate [52]. This in turn is dictated by the density and boiling point of the fuel along with the spreading angle of the spray. n-Heptane features the lowest density and boiling point of the three fuels. The difference in spreading angle between fuels is not large enough to significantly affect the hot gas energy entrainment, even though n-heptane appears to penetrate slightly slower in the vapor penetration curves. The influence of more specific fuel properties over the stabilized liquid length is analyzed further in section 3.4.

\subsection{Spray spreading angle}

The spray tip penetration is closely related to the spray spreading angle $[40,41]$. Larger spreading angles imply more momentum exchange with the ambient gas which, in turn, renders slower spray tip penetration rates downstream. Figure 6 showed that the sprays produced by the cylindrical nozzle penetrate slower when compared to those produced by the conical nozzle, so larger spreading angles should be expected for the former. Figure 8 shows a scatter of vapor spray spreading angle values for all test conditions at $900 \mathrm{~K}$. The spreading angle reported is the angle included between two linear fits performed to the top and bottom halves of the detected spray contour located within $3.6 \mathrm{~mm}$ and $15 \mathrm{~mm}$ axially measured from the nozzle tip (see Figure 3 for an illustration of the angle estimation). The lines fitted are forced to pass through the nozzle outlet. Angle signals from all repetitions are then averaged in the stabilized region of the injection event, from $1 \mathrm{~ms}$ to $3 \mathrm{~ms}$ after SOI, to obtain a single value per test in order to make comparisons for analysis.

The spreading angle was not found to be significantly affected by the rail pressure, as seen previously by the authors [40, 41] and also found in the literature [59, 60]. Increasing ambient density, on the other hand, increases

spreading angle accordingly. Still, the effect of the nozzle geometry was 


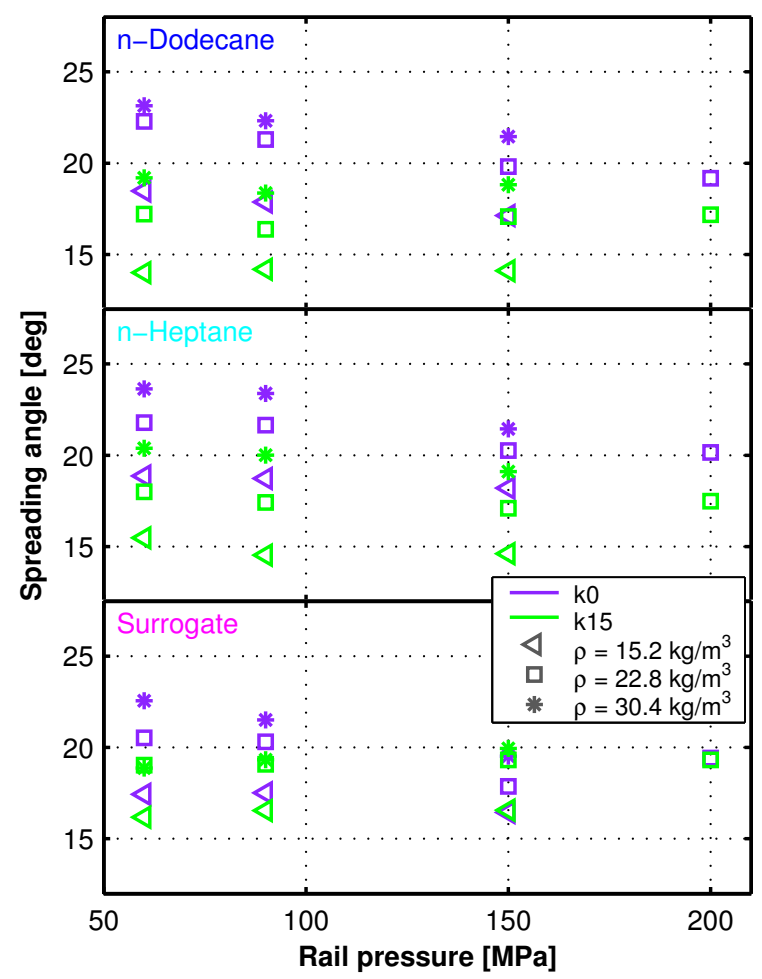

Figure 8: Time-averaged spray spreading angles for all test conditions at $900 \mathrm{~K}$. 
found to be as significant as the effect of ambient density, with the cylindrical nozzle $k 0$ showing larger spreading angles along the full test matrix. This result is in agreement with the previous findings of the authors for nonevaporative isothermal sprays $[40,41]$. Moreover, note how fuels do not seem to show clear trends affecting the spreading angle. This is in agreement with the gas jet theory, but contradicts the behavior found by the authors with the same nozzles and fuels for non-evaporative isothermal sprays [41], where n-heptane showed larger spreading angles through the test matrix due to its lower density, viscosity and surface tension. The results of the present study put together with those presented by Payri et al. [41] for the same nozzles and fuels mark a clear difference between the liquid isothermal nonevaporative spray and the vapor spray. Even though Figure 8 only presents spreading angle results for ambient temperatures of $900 \mathrm{~K}$, the trends found were similar at $800 \mathrm{~K}$ and $970 \mathrm{~K}$. Note that all data is available for download at: http://www.cmt.upv.es/DD01.aspx.

\subsection{Liquid penetration length for different nozzles and fuels}

From all time-resolved liquid penetration signals, a time-averaged single value can be extracted to synthesize the liquid length response to the different variables tested into simpler information. From this point forward, all liquid length values presented correspond to those obtained by averaging the liquid penetration signals from $1 \mathrm{~ms}$ to $3 \mathrm{~ms}$ after SOI. Note that temperatures and densities plotted are not the nominal set points but instead measurements or estimations from the actual during-test conditions.

Figure 9 presents a select group of liquid length values for all nozzles and fuels along an ambient temperature sweep, at the central ambient density of $22.8 \mathrm{~kg} / \mathrm{m}^{3}$ and the two limits of rail pressure tested: $60 \mathrm{MPa}$ and $200 \mathrm{MPa}$. As expected, liquid lengths are inversely proportional to ambient temperature [52], because the hotter ambient gas entrained provides more energy for the vaporization of a given mass of fuel. The cylindrical nozzle $k 0$ features shorter liquid lengths through the full test matrix, but its effect on liquid length is reduced with increasing injection pressure, as shown by Figure 9-top and bottom respectively. This could be explained by the observations of vapor spray tip penetration presented in section 3.2 .2 (see Figure 6), where the effect of nozzle geometry on spray penetration is more important at lower rail pressures because of the longer time needed for the fuel to reach a certain penetration length, and because of the smaller quantity of gas entrained, when compared to very high rail pressure cases. The 
smaller quantity of gas entrained make the nozzle outlet conditions more relevant to the momentum exchange, and the longer time needed to reach a certain penetration length allow for the momentum exchange to be amplified by the turbulent velocity profiles at the nozzle outlet, which consequently renders a shorter liquid lengths for the cylindrical nozzle $k 0$. Note that similar observations - regarding the effect of nozzle geometry and rail pressure over the spray development-were reported by the authors in previous experiments of liquid non-evaporative sprays of the same nozzles and fuels [41].

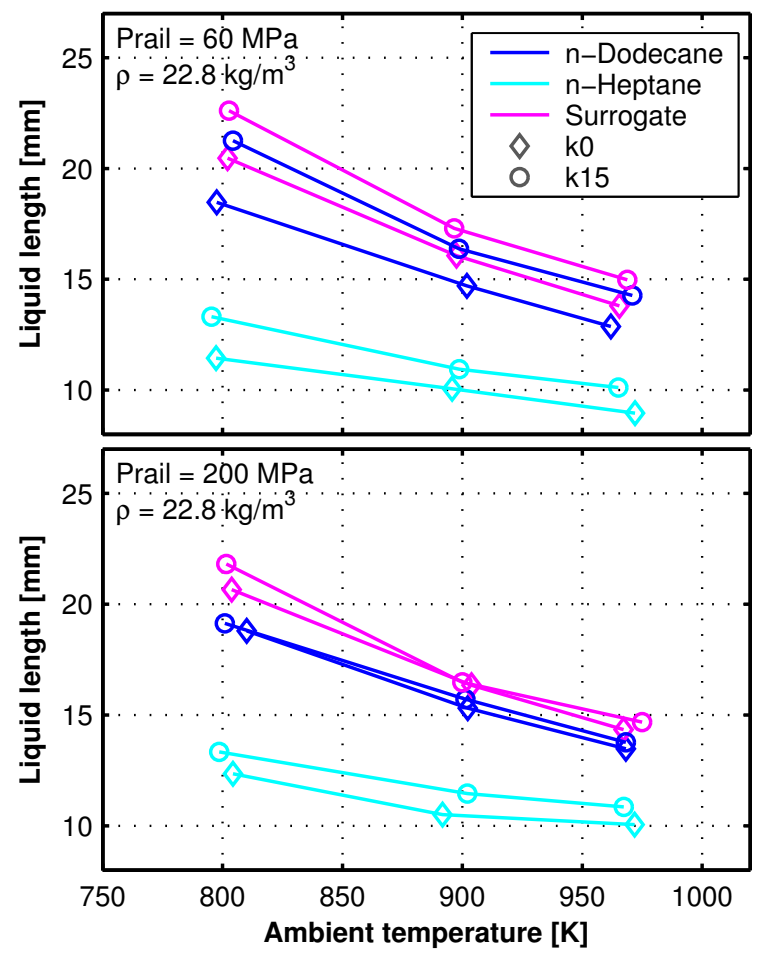

Figure 9: Time-averaged liquid length values for all nozzles and fuels along an ambient temperature sweep.

Figure 9 also shows a clear separation between the liquid lengths produced by the three fuels tested. In similar conditions, n-heptane produces sprays with considerably shorter liquid length than n-dodecane, which is followed by the Surrogate fuel. This was already depicted in Figures 4 and 7 for particular test conditions, synthesized here for a larger data set and is also seen in Figure 10 for different ambient densities. The main drivers of these trends are the 
thermodynamic properties and density of each fuel, with n-heptane featuring lower density and boiling point than n-dodecane and all components of the Surrogate fuel. Note that these results agree with the literature: the liquid length of the Surrogate fuel is controlled by its heavier components, and thus, it results longer than the liquid length of n-dodecane [52, 53, 61], even though the Surrogate starts to evaporate earlier at atmospheric conditions.

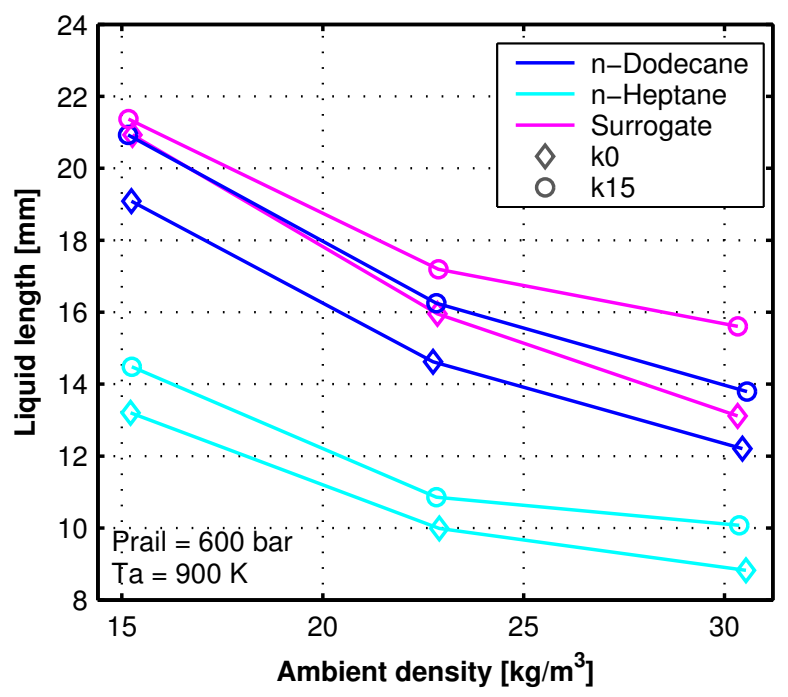

Figure 10: Time-averaged liquid length values for all nozzles and fuels along an ambient density sweep.

The effect of ambient density is synthesized in Figure 10. As expected, liquid lengths are inversely proportional to ambient density [52]. Note that the trends for nozzle geometry and fuel effects remain, as already discussed.

Properly predicting liquid lengths is of great interest for combustion chamber development. Siebers [61] presented a scaling law based in the fundamental physical processes that take place in the evaporative spray, allowing for fast predictions of liquid length for single-component fuels. Higgins et al. [53] proposed an alternative model which considers multi-component fuels, through basic thermodynamic properties of each component at reference conditions:

$$
x_{l i q}=k A^{\alpha} B^{\beta} d_{o}
$$

Where $k$ is a proportioning constant, $A=\sqrt{\rho_{f} / \rho}$ is the density ratio, 
and $B$ is the specific energy ratio, calculated as:

$$
B=\frac{\sum_{i=1}^{N} m_{i} h_{v a p, i}+\left(T_{b, \max }-T_{f}\right) \sum_{i=1}^{N} m_{i} C_{p, l i q, i}}{C_{p, a i r}\left(T_{a}-T_{b, \max }\right) \sum_{i=1}^{N} m_{i}}
$$

Where $T_{b, \max }$ is the maximum $T_{b}$ among the $N$ species and $m_{i}$ is the mass fraction of species $i$. Note that $A$ and $B$ are evaluated using the atmospheric properties of the fuel, which is very convenient. Fuel properties utilized for the evaluation of the $A$ and $B$ terms are summarized in Tables 2 and 3 . Fuel temperature at the outlet orifice was estimated from the data collected previously by Payri et al. [46]. Higgins et al. [53] proposed values for $k, \alpha$ and $\beta$ but these not necessarily apply for any nozzle, fuel, and/or outside the test conditions covered. Moreover, this model would not predict properly the effect of nozzle geometry. The effect of nozzle geometry could be included by introducing the effective diameter instead of the nominal diameter $\left(d_{e f f}=\right.$ $d_{o} \sqrt{C_{a}}$ ), so Eq. (2) can be re-written:

$$
x_{l i q}=k A^{\alpha} B^{\beta} d_{o} \sqrt{C_{a}}
$$

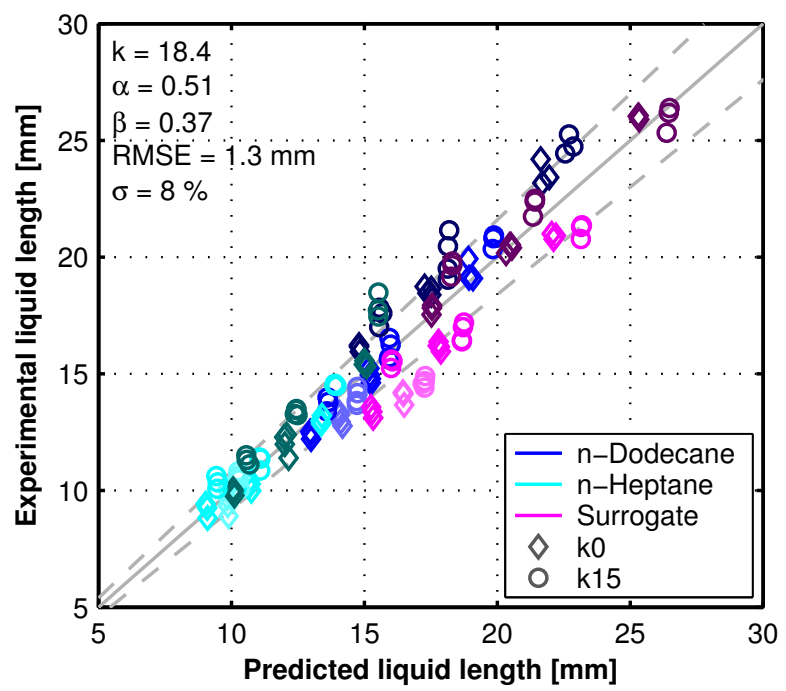

Figure 11: Non-linear regression of the model originally presented by Higgins et al. [53], modified to include the effect of nozzle geometry, presented in Eq. (4). Dashed lines represent $\pm \sigma$.

Where $C_{a}$ is the area coefficient, previously measured by the authors for 
all nozzles and fuels [41]. This model was employed to predict all liquid length values measured, and the results are presented in Figure 11. In this figure, nozzles are denoted by symbols while fuels are distinguished by color (For interpretation of the references to color in this figure legend, the reader is referred to the web version of this article). Each color is shaded so that ambient temperatures are differentiable, if such is the intent of the reader. The regression coefficients are shown in the top-left corner of the figure, along with the root-mean-square error (RMSE) of the fit. Note how the effect of ambient density is very well captured, with $\alpha=0.51$ when mixing-limited models predict a value of 0.5 [61]. Considering how little data is needed to use Eq. (4) for these fast liquid length predictions, these are acceptable results, with the RMSE low at $1.3 \mathrm{~mm}$. However, Figure 11 demonstrates that even though the effect of nozzle geometry is partially captured by the model, there is still an offset from the main diagonal when comparing nozzles at equal conditions. Hence, Eq. (4) can be modified further by introducing vapor spray spreading angles (presented in Figure 8):

$$
x_{l i q}=k d_{o} \sqrt{C_{a}} A^{\alpha} B^{\beta} \tan ^{\phi}(\theta / 2)
$$

For this regression, the coefficient defining the effect of ambient density $(\alpha)$ was fixed to 0.5 to comply with the mixing-limited evaporative spray theory [61] and reduce the degrees of freedom of the regression. The results from this non-linear fit are presented in Figure 12. Note that the coefficient for the spreading angle results negative, which is expected since larger angles would produce shorter liquid lengths. Note also that the $\beta$ coefficient remains the same as in the previous model, but now the effect of nozzle geometry is captured better, which then reduces the RMSE. Still, the behavior of the Surrogate is not completely well captured by the model, even though this fuel is the original reason why the model was implemented. Fuel properties in Tables 2 and 3 indicate that all fuels tested in this study feature comparable specific heats and enthalpies of vaporization. The significant differences between fuels are actually the boiling points. Higgins et al. [53] demonstrated that considering only $T_{90}$ - or simply, the boiling point for single-component fuels - may not be an appropriate approach for some fuels, for instance, methanol. Alcohols in general feature considerably larger enthalpies of vaporization than hydrocarbons [53, 62], which means that, even though their boiling points may be lower, complete evaporation requires far more energy entrained into the spray, which translates into longer length 
scales [53, 62]. However, Higgins et al. [53] also observed a good correlation between predicted liquid lengths and $T_{90}$ for a large group of other fuels. In the case of this study, considering fuel properties in Tables 2 and 3 and that all fuels are hydrocarbons, it would be reasonable to think that even a simpler model would be equally suited to properly predict liquid lengths.

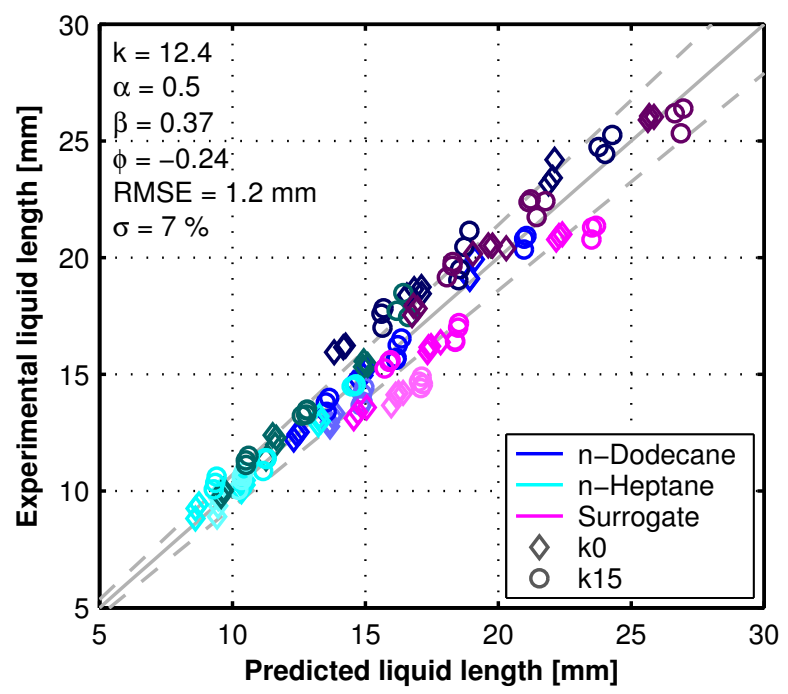

Figure 12: Non-linear regression of the model originally presented by Higgins et al. [53], modified to include the effect of nozzle geometry and vapor spray spreading angle, presented in Eq. (5). Dashed lines represent $\pm \sigma$.

$$
x_{l i q}=k d_{o} \sqrt{C_{a}} A^{\alpha} T_{a}^{b} T_{90}^{c} \tan ^{\phi}(\theta / 2)
$$

A simpler model is presented in Eq. (6). This engineering correlation separates the contributions of $T_{90}$ and $T_{a}$ into two degrees of freedom. Once more, the coefficient for the density ratio $A$ was fixed to 0.5 . Note that the regression coefficient for the spreading angle $(\phi)$ resulted in a value relatively close to the value obtained for the model presented in Eq. (5). Note also that the relationship between the predicted liquid length and $T_{90}$ is practically linear, and that liquid length is inversely proportional to the ambient temperature squared. This model, even though simpler, results more convenient for the case of study since it captures better the behavior of the different fuels, while still reproducing reasonably the effect of nozzle geometry. 


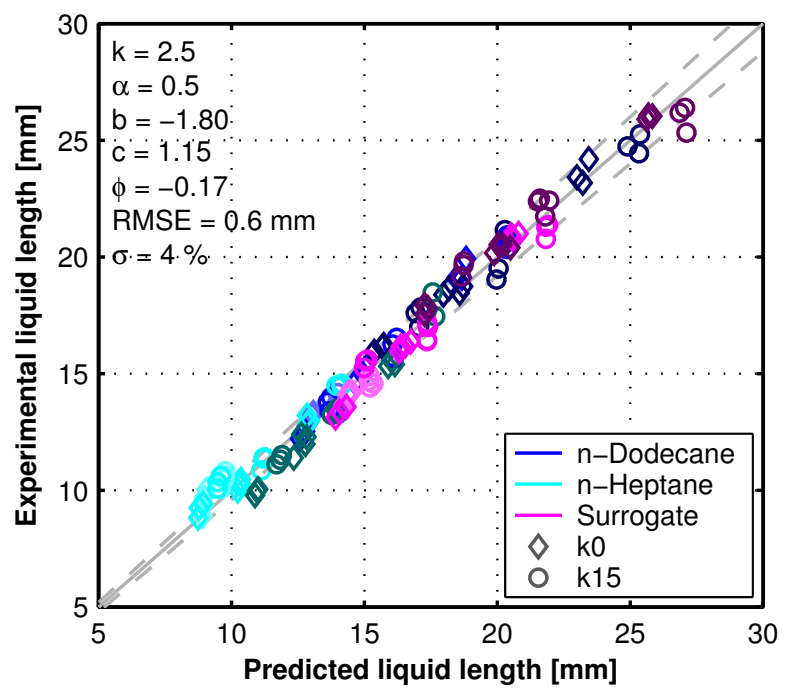

Figure 13: Results of the non-linear regression of the engineering correlation presented in Eq. (6). Dashed lines represent $\pm \sigma$.

\subsection{Spray boundary fluctuations}

Payri et al. [40] presented line-of-sight fluctuation maps of the detected spray boundaries, which clearly marked differences between the cylindrical and conical nozzle for liquid non-evaporative isothermal n-dodecane sprays. Later, Payri et al. [41] presented similar maps for the same non-evaporative sprays, but then showing also the three fuels tested in this study. These maps illustrated how the cylindrical nozzle widens the liquid spray immediately after the fuel has exited the orifice, while the spray produced by the conical nozzle spreads more progressively downstream. Spray boundary fluctuations were also found to be greater for the cylindrical nozzle. Moreover, these maps showed that the liquid non-evaporative isothermal n-heptane spray featured larger spreading angle and fluctuations in the boundary region, followed by the Surrogate spray. This section discusses analogous maps which are constructed from the spray boundaries of the liquid and vapor phases separately detected, to asses if the conclusions drawn from the liquid non-evaporative isothermal sprays are carried on to hot evaporative sprays.

Figure 14 shows line-of-sight fluctuation maps of liquid sprays produced by the two nozzles and three fuels at a particular case of test conditions. Each map is calculated as the standard deviation between all binary images of the detected sprays from the corresponding test. Examples of the binary 


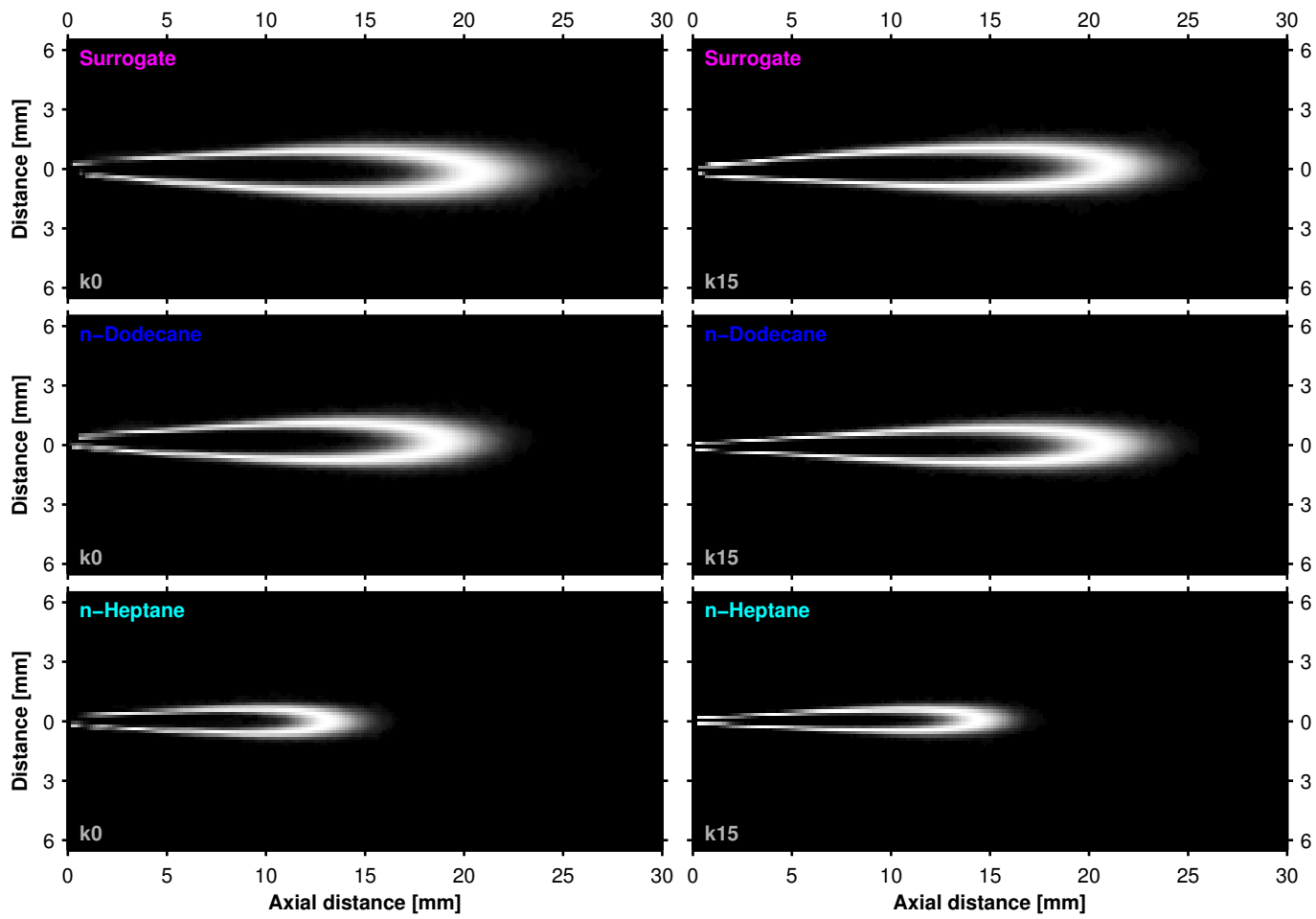

Figure 14: Liquid spray fluctuation maps for all nozzles and fuels at a rail pressure of 60.0 MPa, an ambient density of $15.2 \mathrm{~kg} / \mathrm{m}^{3}$, and an ambient temperature of $900 \mathrm{~K}$. Maps comprise all test repetitions and images from $0.5 \mathrm{~ms}$ after SOI to the end of the signals. 
images can be found in the work of Payri et al. [43]. This calculation is done past $0.5 \mathrm{~ms}$ after SOI to guarantee that the spray is in steady state. Therefore, a black pixel corresponds to a non-fluctuating location: the spray never occupies that pixel or the pixel is always considered to be within the spray during the time window considered. On the other hand, the brighter a pixel is, the more likely it is for fluctuations to occur at that location (and/or the stronger fluctuations at that location are) and, as expected, this happens near the spray boundary.

The first important observation that Figure 14 provides is that the spray produced by the cylindrical nozzle $k 0$ spreads immediately after the fuel has exited the orifice, while the spray produced by nozzle $k 15$ starts thin and spreads progressively downstream, as previously seen in non-evaporative isothermal sprays $[40,41]$. This implies that the nozzle geometry has great effect on what Benajes et al. [63] refer to as transitional length, which is the region after the intact liquid core starts to break but before the spray starts its linear evolution. Moreover, fluctuation maps for $k 0$ are more diffuse in the radial direction, which indicates larger fluctuations, which was also seen by Payri et al. [40, 41] in the non-evaporative isothermal case. Since the evaporative sprays are small relative to the spatial resolution achieved, no important differences could be observed between fuels in terms of fluctuations as presented here.

Still, observing these two-dimensional maps directly complicates the direct comparison between nozzles. If these maps are integrated from $1 \mathrm{~mm}$ to $9 \mathrm{~mm}$ along the spray axis, a quantitative measurements of the fluctuation strength and area can be synthesized into a single value - which will be referred to as "fluctuation power" - per test condition, nozzle and fuel [40]. Note that the integration excludes the tip region, to exclude fluctuations in the liquid length, which are out of the scope of this publication [64]. Liquid spray fluctuation power values are presented in Figure 15 for all nozzles and fuels at an ambient temperature of $900 \mathrm{~K}$. Payri et al. [40] presented and similar analysis for non-evaporative isothermal sprays, showing that fluctuation power was directly proportional to ambient density, due to the increased turbulence and momentum exchange, and that the cylindrical nozzle featured larger values at equal injection conditions. In the case of evaporative sprays, larger ambient densities a translated into smaller liquid sprays, so fluctuation power values are slightly reduced due to the decrease in line-of-sight area in the radial direction. Still, Figure 15 shows that, generally, fluctuation power values are scaled with ambient density, similarly to 
the non-evaporative isothermal case, even though the higher ambient density sprays are smaller in projected area. Also, the cylindrical nozzle $k 0$ features larger fluctuation power values all through the test matrix when compared to the conical nozzle $k 15$ at equal test conditions, which results from a combination of the wider spray produced and a more diffuse fluctuation map. Note that the effect of ambient density over each fuel is not constant. The Surrogate fuel liquid spray seems to be less affected by changes in ambient density, which could be related to its higher density, viscosity and surface tension, all which help the liquid droplets to conserve momentum. n-Heptane, on the other hand, seems to be more affected by changes in ambient density, with $\mathrm{n}$-dodecane in the middle, which agrees with the non-evaporative isothermal spray results presented previously by the authors [41].

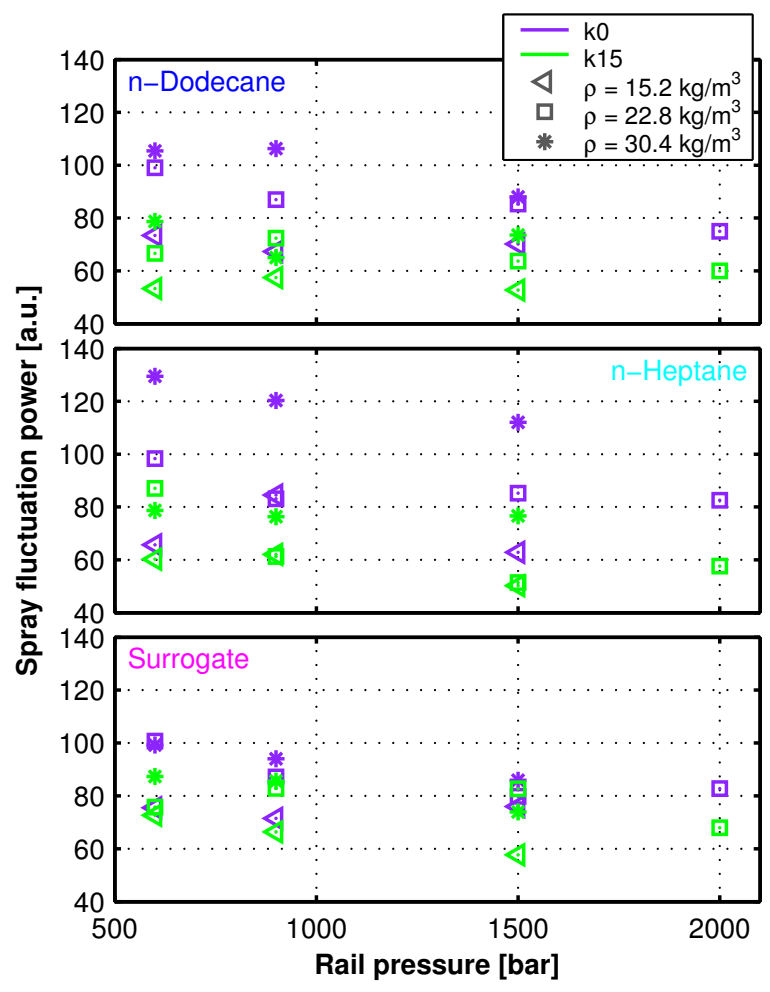

Figure 15: Liquid spray fluctuation power from $1 \mathrm{~mm}$ to $9 \mathrm{~mm}$ along the spray axis, at an ambient temperature of $900 \mathrm{~K}$.

A similar analysis can be carried out for the vapor phase, which should agree with the penetration and spreading angle observations already pre- 
sented, as was the case for non-evaporative isothermal sprays [41]. Lineof-sight fluctuation maps of vapor sprays are presented in Figure 16 for all nozzles and fuels at a particular case of test conditions. Plots in the left column demonstrate that the cylindrical nozzle $k 0$ produces vapor sprays which spread immediately after exiting the orifice, while the conical nozzle produces a thin jet that spreads more progressively downstream, which again suggests that the nozzle geometry is affecting the transitional length [63]. Note that this result is in agreement with the findings for the liquid phase presented here, and those found for non-evaporative isothermal sprays analyzed previously by the authors, for the same nozzles and fuels [41]. As in the liquid phase case, the cylindrical nozzle $k 0$ produces not only wider sprays but also more diffuse fluctuation maps, which indicates larger fluctuations in the line-of-sight spray boundaries detected. The vapor phase fluctuation maps are not as diffuse - statistically evenly distributed - near the spray boundary as the liquid phase maps or those presented previously by Payri et al. $[40,41]$, due to the lower frame rate of the camera in this particular setup, which translates into smaller total number of frames from which to extract the maps.

Analogous to the liquid phase case, these maps can be integrated from $3.6 \mathrm{~mm}$ to $50 \mathrm{~mm}$ along the spray axis to synthesize part of these maps into a single fluctuation power value per test conditions. Note that $3.6 \mathrm{~mm}$ is selected as the lower limit since it is the same limit used for the calculation of the vapor spray spreading angles presented in Figure 8. Vapor spray fluctuation power values are presented in Figure 17 for all nozzles and fuels at an ambient temperature of $900 \mathrm{~K}$. In general, fluctuation power values for the vapor spray are also scaled with ambient density, and remain larger for the cylindrical nozzle $k 0$ when compared to the conical nozzle $k 15$. In contrast to the liquid phase results presented in Figure 15, the different fuels were not found to respond in significantly different ways - in terms of fluctuations - to changes in ambient density, which is in agreement with the spray tip penetration observations for evaporative sprays presented in this study. Again, this was not the case for the non-evaporative isothermal sprays studied previously [41].

Observations presented in this study, along with previous conclusions gathered by the authors for the same nozzle and fuels [41] suggest that the vapor spray is indeed controlled by momentum and turbulence conditions at the nozzle outlet - strongly dictated by nozzle geometry-but the interactions between the vapor phase of the spray and the ambient gas are not 

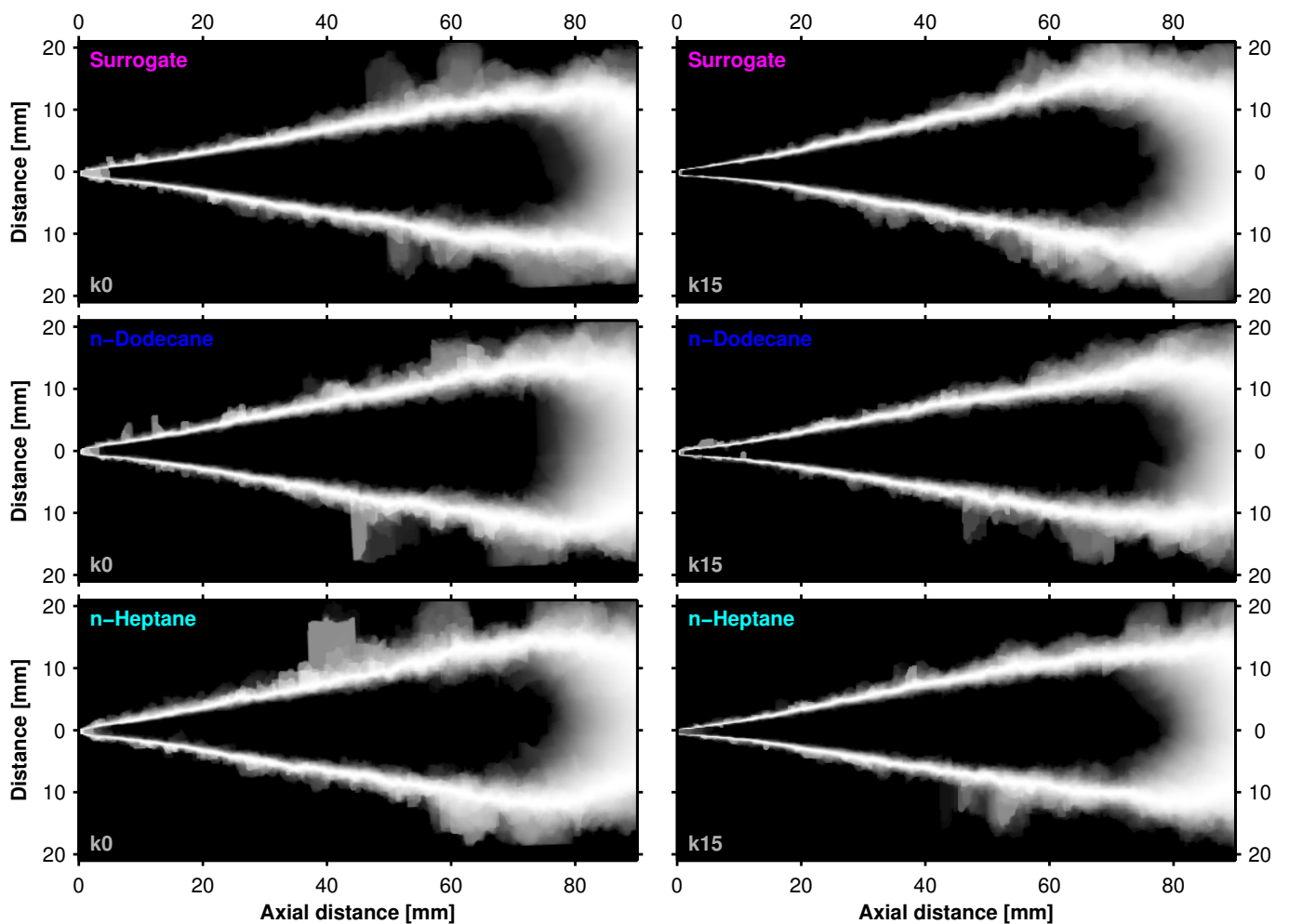

Figure 16: Vapor spray fluctuation maps for all nozzles and fuels at a rail pressure of $60.0 \mathrm{MPa}$, an ambient density of $15.2 \mathrm{~kg} / \mathrm{m}^{3}$, and an ambient temperature of $900 \mathrm{~K}$. The maps comprise all test repetitions and images from $2.5 \mathrm{~ms}$ after SOI to the end of the injections. 


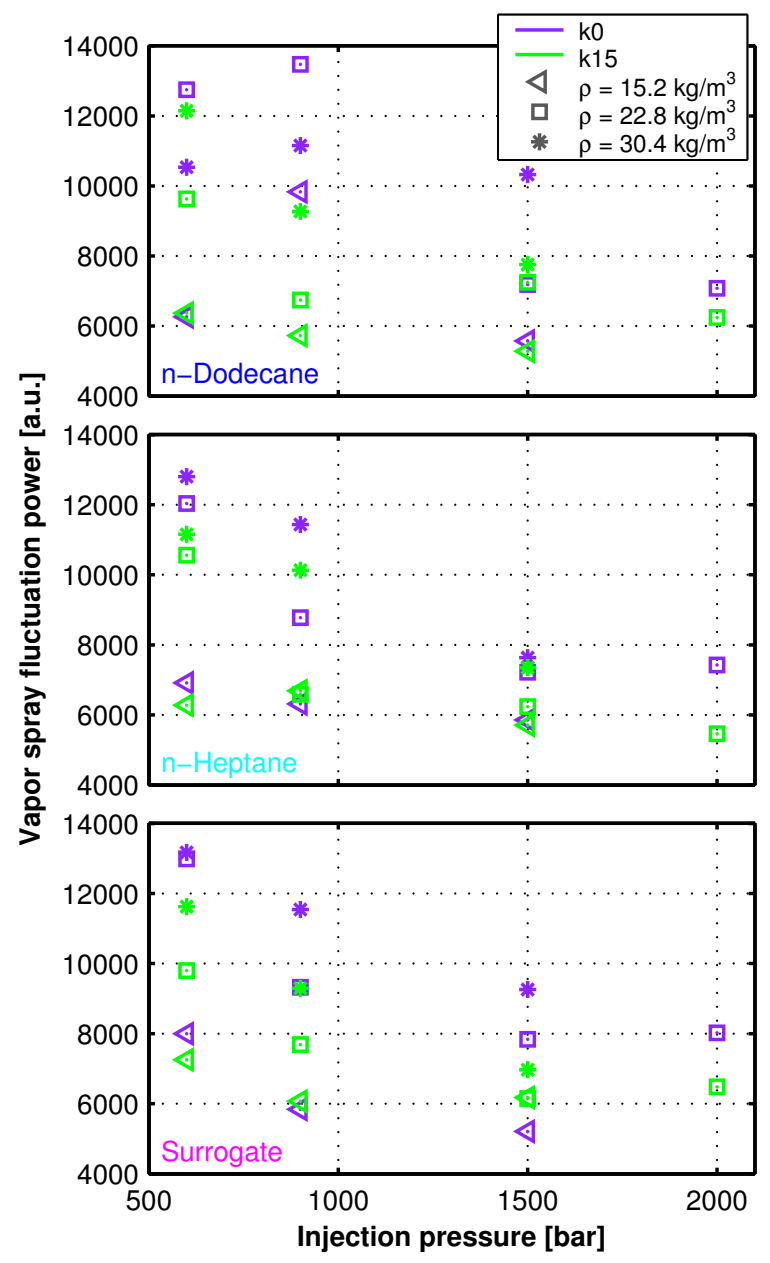

Figure 17: Vapor spray fluctuation power from $3.6 \mathrm{~mm}$ to $50 \mathrm{~mm}$ along the spray axis, at an ambient temperature of $900 \mathrm{~K}$. 
strongly affected by fuel properties, which was not found to be the case for the liquid phase spray in both the evaporative case presented here, and the non-evaporative isothermal case presented previously [41].

\section{Conclusions}

The influence of internal nozzle flow characteristics over the evaporative spray development is studied experimentally for two different nozzle geometries and three different fuels. The macroscopic spray characteristics are obtained by imaging the liquid and vapor phases of the spray simultaneously using independent cameras and optical techniques, and the results are reported in this work. The liquid phase is captured by a fast-pulsed diffused back illumination setup, while the vapor phase is captured by a single-pass Schlieren setup with diaphragm. A conical nozzle and a cylindrical nozzle with $8.6 \%$ larger outlet diameter are included in this study. Among the three fuels, two are pure components - n-heptane and n-dodecane - while the third consists of a three-component surrogate to better represent the physical and chemical properties of diesel fuel.

For a fixed ambient density, the liquid penetration is controlled by the available energy for vaporization (mainly ambient temperature and ambient density) while the vapor penetration is controlled by momentum (mainly rail pressure and ambient density). The cylindrical nozzle, in spite of higher mass flow rate and momentum flux, shows slower vapor spray tip penetration when compared to the conical nozzle. Also, the cylindrical nozzle consistently produced shorter liquid lengths. The vapor spray spreading angle is found to be inversely proportional to the spray tip penetration, largely influenced by the nozzle geometry and the ambient density. n-Heptane spray shows the shortest liquid lengths, followed by n-dodecane and finally the Surrogate. However, no significant difference in vapor penetration rates was found between fuels, confirming that the vapor spray is controlled by momentum, which is independent of fuel. This was not the case for the non-evaporative isothermal sprays previously studied by the authors. Liquid lengths show the expected responses to parametric variations of ambient temperature and density. Two empirical predictive models are presented and utilized to analyze the influence of fuel properties on the liquid length. The primary factor controlling the liquid length between fuels is found to be their volatility. Finally, the cylindrical nozzle exhibits larger line-of-sight contour fluctuations 
in both the liquid and vapor phases, which in turn contributes to the shorter liquid lengths and slower vapor penetration.

The experimental findings from this work on the macroscopic spray behavior, and the large database obtained (available for download at: http: //www. cmt . upv. es/DD01. aspx), could be used to validate CFD models that could help the community understand the fundamental driving mechanisms behind these observations.

\section{Acknowledgments}

This work was sponsored by Ministerio de Economía y Competitividad of the Spanish Government in the frame of the Project "Estudio de la interaccin chorro-pared en condiciones realistas de motor", Reference TRA201567679-c2-1-R. Additionally, the employed nozzles and Diesel surrogate were provided and defined by GM R\&D.

The authors would like to thank José Enrique Del Rey and María del Carmen Tomás for their collaboration in the setup of the experiments and laboratory work, and Guillermo Miró for his help measuring fuel properties.

\section{References}

[1] M. Costa, U. Sorge, L. Allocca, Increasing energy efficiency of a gasoline direct injection engine through optimal synchronization of single or double injection strategies, Energy Conversion and Management 60 (2012) 77-86, ISSN 01968904, doi: \bibinfo\{doi\}\{10.1016/j.enconman.2011.12. 025\}, URL http://dx.doi.org/10.1016/j.enconman.2011.12.025.

[2] T. D. Fansler, S. E. Parrish, Spray measurement technology: a review, Measurement Science and Technology 26 (1) (2015) 012002, ISSN 0957-0233, doi: \bibinfo\{doi\}\{10.1088/0957-0233/ 26/1/012002\}, URL http://stacks.iop.org/0957-0233/26/i=1/a= 012002?key=crossref . a51a57d78742e5d88aea3d6f06688ef c.

[3] C. Badock, R. Wirth, C. Tropea, The influence of hydro grinding on cavitation inside a diesel injection nozzle and primary break-up under unsteady pressure conditions, in: Proc. 15th ILASS-Europe 99, Toulouse, July 5-7, Toulouse (France), 1999. 
[4] L. C. Ganippa, S. Andersson, J. Chomiak, A. Matsson, Combustion characteristics of diesel sprays from equivalent nozzles with sharp and rounded inlet geometries, Combustion Science and Technology 175 (6) (2003) 1015-1032, ISSN 0010-2202, doi: \bibinfo $\{$ doi $\}\{10.1080 /$ $00102200302350\}$.

[5] J.-s. Han, P.-h. Lu, X.-b. Xie, M.-c. Lai, N. A. Henein, Investigation of Diesel Spray Primary Break-up and Development for Different Nozzle Geometries, SAE Technical Paper 2002-01-27.

[6] M. Blessing, G. König, C. Krüger, U. Michels, V. Schwarz, Analysis of flow and cavitation phenomena in diesel injection nozzles and its effects on spray and mixture formation, SAE Technical Paper 2003-01-1358 ISSN 1356-1448, doi: \bibinfo\{doi\}\{10.4271/2003-01-1358\}.

[7] H. K. Suh, C. S. Lee, Effect of cavitation in nozzle orifice on the Diesel fuel atomization characteristics, International Journal of Heat and Fluid Flow 29 (4) (2008) 1001-1009, ISSN 0142727X, doi: bibinfo\{doi $\{10$. 1016/j.ijheatfluidflow.2008.03.014\}, URL http: //www. sciencedirect . com/science/article/pii/S0142727X08000623.

[8] S. H. Park, H. K. Suh, C. S. Lee, Effect of Cavitating Flow on the Flow and Fuel Atomization Characteristics of Biodiesel and Diesel Fuels, Energy \& Fuels 22 (1) (2008) 605-613, ISSN 0887-0624, doi: \bibinfo\{doi\}\{10.1021/ef7003305\}, URL http://pubs.acs.org/doi/ abs/10.1021/ef7003305.

[9] S. Som, A. I. Ramírez, S. Aggarwal, A. L. Kastengren, E. El-Hannouny, D. E. Longman, C. F. Powell, P. K. Senecal, Development and validation of a primary breakup model for diesel engine applications, SAE Technical Paper 2009-01-0838 doi: \bibinfo\{doi $\{$ \{10.4271/2009-01-0838\}.

[10] S. Som, S. K. Aggarwal, Effects of primary breakup modeling on spray and combustion characteristics of compression ignition engines, Combustion and Flame 157 (6) (2010) 1179-1193, ISSN 00102180, doi: \bibinfo\{doi\}\{10.1016/j.combustflame.2010.02.018\}, URL http://dx. doi .org/10.1016/j. combustflame.2010.02.018.

[11] Z. Liu, K.-S. Im, Y. Wang, K. Fezzaa, J. Wang, X.-B. Xie, M.-C. Lai, Near-Nozzle Structure of Diesel Sprays Affected by Internal Geometry 
of Injector Nozzle: Visualized by Single-Shot X-ray Imaging, SAE Technical Paper 2010-01-0877 doi:〈bibinfo $\{$ doi $\}\{10.4271 / 2010-01-0877\}$.

[12] R. Morgan, J. Wray, D. A. Kennaird, C. Crua, M. R. Heikal, The Influence of Injector Parameters on the Formation and break-Up of a Diesel Spray, SAE Technical Paper 2001-01-0529 .

[13] F. Payri, V. Bermúdez, R. Payri, F. J. Salvador, The influence of cavitation on the internal flow and the spray characteristics in diesel injection nozzles, Fuel 83 (4-5) (2004) 419-431, ISSN 00162361, doi: \bibinfo $\{$ doi $\}\{10.1016 /$ j.fuel.2003.09.010\}, URL http://www.sciencedirect.com/science/article/ B6V3B-49S6P9B-1/2/9f0f82ab914af7a5db32ee0c133d7e7d.

[14] W. Ning, R. D. Reitz, R. Diwakar, A. M. Lippert, A Numerical Investigation of Nozzle Geometry and Injection Condition Effects on Diesel Fuel Injector Flow Physics, SAE Technical Paper 2008-01-0936 doi: \bibinfo\{doi\}\{10.4271/2008-01-0936\}.

[15] R. Payri, F. J. Salvador, J. Gimeno, L. D. Zapata, Diesel nozzle geometry influence on spray liquid-phase fuel penetration in evaporative conditions, Fuel 87 (7) (2008) 1165-1176, ISSN 00162361, doi:\bibinfo\{doi\} \{10.1016/j.fuel.2007.05.058\}, URL http://www.sciencedirect.com/ science/article/pii/S0016236107003080.

[16] S. Som, A. I. Ramírez, D. E. Longman, S. K. Aggarwal, Effect of nozzle orifice geometry on spray, combustion, and emission characteristics under diesel engine conditions, Fuel 90 (3) (2011) 1267-1276, ISSN 00162361, doi: \bibinfo \{doi\}\{10.1016/j.fuel.2010.10.048\}, URL http:// dx.doi.org/10.1016/j.fuel.2010.10.048.

[17] A. Montanaro, M. Migliaccio, L. Allocca, V. Fraioli, S.-y. Lee, A. Zhang, J. Naber, Schlieren and Mie Scattering Visualization for Single- Hole Diesel Injector under Vaporizing Conditions with Numerical Validation, SAE Technical Paper 2014-01-1406 2014-01-14, doi: bibinfo\{doi $\}\{10$. 4271/2014-01-1406.Copyright\}.

[18] A. Zhang, A. Montanaro, L. Allocca, J. Naber, S.-Y. Lee, Measurement of Diesel Spray Formation and Combustion upon Different Nozzle Geometry using Hybrid Imaging Technique, SAE Technical Pa- 
per 2014-01-1410 doi:〈bibinfo $\{$ doi $\}\{10.4271 / 2014-01-1410\}$, URL http: //www.sae.org/technical/papers/2014-01-1410.

[19] M. Battistoni, C. Grimaldi, F. Mariani, Coupled Simulation of Nozzle Flow and Spray Formation Using Diesel and Biodiesel for CI Engine Applications, SAE Technical Paper 2012-01-1267 doi: bibinfo\{doi $\}\{10$. 4271/2012-01-1267\}, URL http://www.sae.org/technical/papers/ 2012-01-1267.

[20] J. M. Desantes, R. Payri, J. Gimeno, P. Marti-Aldaravi, Simulation of the First Millimeters of the Diesel Spray by an Eulerian Spray Atomization Model Applied on ECN Spray A Injector, SAE Technical Paper 2014-01-1418 doi: \bibinfo\{doi\}\{10.4271/2014-01-1418\}, URL http://papers.sae.org/2014-01-1418/.

[21] M. Battistoni, Q. Xue, S. Som, E. Pomraning, Effect of Off-Axis Needle Motion on Internal Nozzle and Near Exit Flow in a Multi-Hole Diesel Injector, SAE International Journal of Fuels and Lubricants 7 (1) (2014) 2014-01-1426, ISSN 1946-3960, doi:\bibinfo\{doi\}\{10.4271/ 2014-01-1426\}, URL http://papers .sae.org/2014-01-1426/.

[22] F. J. Salvador, J. Gimeno, J. M. Pastor, P. Martí-Aldaraví, Effect of turbulence model and inlet boundary condition on the diesel spray behavior simulated by an eulerian spray atomization (ESA) model, International Journal of Multiphase Flow 65 (2014) 108-116, ISSN 03019322, doi: \bibinfo\{doi\}\{10.1016/j.ijmultiphaseflow.2014.06.003\}, URL http: //dx.doi.org/10.1016/j.ijmultiphaseflow.2014.06.003.

[23] Q. Xue, S. Som, M. Battistoni, S. Quan, P. K. Senecal, E. Pomraning, D. Schmidt, Eulerian CFD Modeling of Coupled Nozzle Flow and Spray with Validation Against X-Ray Radiography Data, Int. J. of Engines 7 (2) (2014) 1061-1072, ISSN 19463944, doi: bibinfo\{doi $\}\{10$. 4271/2014-01-1425\}.

[24] Q. Xue, M. Battistoni, C. F. Powell, D. E. Longman, S. Quan, E. Pomraning, P. K. Senecal, D. P. Schmidt, S. Som, An Eulerian CFD model and X-ray radiography for coupled nozzle flow and spray in internal combustion engines, International Journal of Multiphase Flow 70 (2015) 77-88, ISSN 03019322, doi:〈bibinfo\{doi\}\{10.1016/ 
j.ijmultiphaseflow.2014.11.012\}, URL http://linkinghub.elsevier. com/retrieve/pii/S0301932214002328.

[25] J. M. Desantes, J. M. García-Oliver, J. M. Pastor, A. Pandal, E. Baldwin, D. P. Schmidt, Coupled/decoupled spray simulation comparison of the ECN spray a condition with the $\Sigma$-Y Eulerian atomization model, International Journal of Multiphase Flow 80 (2016) 89-99, ISSN 03019322, doi:\bibinfo\{doi\}\{10.1016/j.ijmultiphaseflow.2015.12.002\}.

[26] M. Bardi, R. Payri, L. M. Malbec, G. Bruneaux, L. M. Pickett, J. Manin, T. Bazyn, C. L. Genzale, Engine Combustion Network: Comparison of Spray Development, Vaporization, and Combustion in Different Combustion Vessels, Atomization and Sprays 22 (10) (2012) 807-842, ISSN 1044-5110, doi: bibinfo\{doi\}\{10.1615/AtomizSpr.2013005837\}, URL http://www.dl . begellhouse.com/journals/6a7c7e10642258cc, 5b18f0e860ebc687, 20adc8ff175d5f43.html.

[27] H. Curran, P. Gaffuri, W. J. Pitz, C. Westbrook, A Comprehensive Modeling Study of n-Heptane Oxidation, Combustion and Flame 114 (1-2) (1998) 149-177, ISSN 00102180, doi: bibinfo\{doi $\}\{10$. 1016/S0010-2180(97)00282-4\}, URL http://linkinghub.elsevier. com/retrieve/pii/S0010218097002824.

[28] J. T. Farrell, N. P. Cernansky, F. L. Dryer, C. K. Law, D. G. Friend, C. A. Hergart, R. M. McDavid, A. K. Patel, C. J. Mueller, H. Pitsch, Development of an Experimental Database and Kinetic Models for Surrogate Diesel Fuels, SAE Technical Paper 2007-01-0201 doi: $\backslash$ bibinfo\{doi\}\{10.4271/2007-01-0201\}, URL http://papers.sae.org/ 2007-01-0201/.

[29] F. Battin-Leclerc, Detailed chemical kinetic models for the lowtemperature combustion of hydrocarbons with application to gasoline and diesel fuel surrogates, Progress in Energy and Combustion Science 34 (2008) 440-498, ISSN 03601285, doi:〈bibinfo\{doi\}\{10.1016/j.pecs. 2007.10.002\}.

[30] M. Raju, M. Wang, P. K. Senecal, S. Som, D. E. Longman, A reduced diesel surrogate mechanism for compression ignition engine applications, in: Proceedings of the ASME 2012 Internal Combustion Engine Division 
Fall Technical Conference ICEF2012, American Society of Mechanical Engineers, Vancouver, doi: \bibinfo\{doi\}\{ICEF2012-92045\}, 2012.

[31] R. H. Natelson, M. S. Kurman, N. P. Cernansky, D. L. Miller, Experimental investigation of surrogates for jet and diesel fuels, Fuel 87 (2008) 2339-2342, doi: bibinfo\{doi\}\{10.1016/j.fuel.2007.11.009\}.

[32] W. J. Pitz, C. J. Mueller, Recent progress in the development of diesel surrogate fuels, Progress in Energy and Combustion Science 37 (3) (2011) 330-350, ISSN 0360-1285, doi: \bibinfo $\{$ doi $\}\{10.1016 / j \cdot p e c s .2010$. 06.004\}, URL http://dx.doi.org/10.1016/j.pecs.2010.06.004.

[33] H. Pitsch, H. Barths, N. Peters, Three-dimensional Modeling of NOx and soot formation in DI-diesel engines using detailed chemistry based on the interactive flamelet approach, SAE Technical Paper 962057 doi: $\backslash$ bibinfo $\{$ doi $\}\{10.4271 / 962057\}$.

[34] J. Luo, M. Yao, H. Liu, B. Yang, Experimental and numerical study on suitable diesel fuel surrogates in low temperature combustion conditions, Fuel 97 (2012) 621-629, ISSN 0016-2361, doi: bibinfo $\{$ doi $\}\{10$. 1016/j.fuel.2012.02.057\}, URL http://dx.doi.org/10.1016/j.fuel. 2012.02 .057$.

[35] C. A. Idicheria, L. M. Pickett, Soot formation in Diesel combustion under high-EGR conditions, SAE Technical Paper 2005-01-3834 doi: \bibinfo $\{$ doi $\}\{10.4271 / 2005-01-3834\}$.

[36] S. Som, S. K. Aggarwal, E. M. El-Hannouny, D. E. Longman, Investigation of nozzle flow and cavitation characteristics in a diesel injector, Journal of Engineering for Gas Turbines and Power 132 (4) (2010) 042802, doi: \bibinfo\{doi $\}\{10.1115 / 1.3203146\}$.

[37] R. Payri, F. J. Salvador, J. Gimeno, O. Venegas, Study of cavitation phenomenon using different fuels in a transparent nozzle by hydraulic characterization and visualization, Experimental Thermal and Fluid Science 44 (2013) 235-244, ISSN 0894-1777, doi: \bibinfo\{doi\} \{10.1016/j.expthermflusci.2012.06.013\}, URL http://dx.doi.org/10 . 1016/j . expthermflusci.2012.06.013. 
[38] G. Jiang, Y. Zhang, H. Wen, G. Xiao, Study of the generated density of cavitation inside diesel nozzle using different fuels and nozzles, Energy Conversion and Management 103 (2015) 208-217, ISSN 01968904, doi: bibinfo\{doi\}\{10.1016/j.enconman.2015.06.065\}, URL http://dx. doi.org/10.1016/j. enconman.2015.06.065.

[39] P.-c. Chen, W.-c. Wang, W. L. Roberts, T. Fang, Spray and atomization of diesel fuel and its alternatives from a single-hole injector using a common rail fuel injection system, Fuel 103 (2013) 850-861, ISSN 00162361, doi:〈bibinfo\{doi\}\{10.1016/j.fuel.2012.08.013\}, URL http://dx . doi.org/10.1016/j.fuel.2012.08.013.

[40] R. Payri, F. J. Salvador, J. Gimeno, J. P. Viera, Experimental analysis on the influence of nozzle geometry over the dispersion of liquid n-dodecane sprays, Frontiers in Mechanical Engineering 1 (2015) 1-10, ISSN 2297-3079, doi: \bibinfo $\{$ doi $\}\{10.3389 /$ fmech.2015. 00013\}, URL http://journal.frontiersin.org/Article/10.3389/ fmech.2015.00013/abstract.

[41] R. Payri, J. P. Viera, V. Gopalakrishnan, P. G. Szymkowicz, The effect of nozzle geometry over internal flow and spray formation for three different fuels, In-press in Fuel .

[42] M. Meijer, B. Somers, J. Johnson, J. Naber, S.-Y. Lee, L. M. Malbec, G. Bruneaux, L. M. Pickett, M. Bardi, R. Payri, T. Bazyn, Engine Combustion Network (ECN): Characterization and comparison of boundary conditions for different combustion vessels, Atomization and Sprays 22 (9) (2012) 777-806, ISSN 10445110, doi: $\backslash$ bibinfo\{doi $\{\{10.1615 /$ AtomizSpr.2012006083\}, URL http://www.dl. begellhouse.com/journals/6a7c7e10642258cc, 64b3d5d415f8eb91, 0365a5274d55553b.html.

[43] R. Payri, J. Gimeno, J. P. Viera, A. H. Plazas, Needle lift profile influence on the vapor phase penetration for a prototype diesel direct acting piezoelectric injector, Fuel 113 (2013) 257265, ISSN 00162361, doi: \bibinfo $\{$ doi $\}\{10.1016 /$ j.fuel.2013.05.057\}, URL http://www.sciencedirect.com/science/article/pii/ S0016236113004699http://dx.doi.org/10.1016/j.fuel.2013.05. 057. 
[44] R. Payri, J. P. Viera, Y. Pei, S. Som, Experimental and numerical study of lift-off length and ignition delay of a two-component diesel surrogate, Fuel 158 (2015) 957-967, ISSN 00162361, doi: $\backslash$ bibinfo\{doi\}\{10.1016/j.fuel.2014.11.072\}, URL http://linkinghub . elsevier.com/retrieve/pii/S0016236114011764.

[45] G. Stumpp, M. Ricco, Common Rail - An attractive fuel injection system for passenger car DI Diesel engines, SAE Technical Paper 960870 doi: $\backslash$ bibinfo $\{$ doi $\}\{10.4271 / 960870\}$.

[46] R. Payri, J. M. Garcia-Oliver, M. Bardi, J. Manin, Fuel temperature influence on diesel sprays in inert and reacting conditions, Applied Thermal Engineering 35 (2012) 185-195, ISSN 1359-4311, doi: $\backslash$ bibinfo\{doi\}\{10.1016/j.applthermaleng.2011.10.027\}, URL doi:10. 1016/j . applthermaleng.2011.10.027.

[47] E. W. Lemmon, M. O. McLinden, D. G. Friend, Thermophysical Properties of Fluid Systems, in: P. J. Linstrom, W. G. Mallard (Eds.), NIST Chemistry WebBook, NIST Standard Reference Database Number 69, URL http://webbook.nist.gov, 2011.

[48] J. Manin, M. Bardi, L. M. Pickett, Evaluation of the liquid length via diffused back-illumination imaging in vaporizing diesel sprays, in: Comodia, Fukuoka, 2012.

[49] L. M. Pickett, C. L. Genzale, J. Manin, Uncertainty quantification for liquid penetration of evaporating sprays at diesel-like conditions, Atomization and Sprays 25 (5) (2015) 425-452, ISSN 1044-5110, doi: \bibinfo\{doi\}\{10.1615/AtomizSpr.2015010618\}, URL http://www.dl . begellhouse.com/journals/6a7c7e10642258cc, 441042be565b52ed, 738986f63f3f0847. html.

[50] Y. Jung, J. Manin, S. A. Skeen, L. M. Pickett, Measurement of Liquid and Vapor Penetration of Diesel Sprays with a Variation in Spreading Angle, SAE Technical Paper 2015-01-0946 doi: \bibinfo\{doi\}\{10.4271/ 2015-01-0946. Copyright\}.

[51] J. Benajes, R. Payri, M. Bardi, P. Martí-aldaraví, Experimental characterization of diesel ignition and lift-off length using a singlehole ECN injector, Applied Thermal Engineering 58 (1-2) (2013) 
554-563, ISSN 13594311, doi: bibinfo\{doi $\}\{10.1016 /$ j.applthermaleng. 2013.04.044\}, URL http://www.sciencedirect.com/science/ article/pii/S1359431113003153http://dx.doi.org/10.1016/j. applthermaleng. 2013.04.044.

[52] D. L. Siebers, Liquid-phase fuel penetration in diesel sprays, SAE Paper 980809 .

[53] B. S. Higgins, C. J. Mueller, D. L. Siebers, Measurements of fuel effects on liquid-phase penetration in DI sprays, SAE transactions 108 (724) (1999) 630-643, doi: $\backslash$ bibinfo $\{$ doi $\}\{10.4271 / 1999-01-0519\}$, URL http: //papers.sae.org/1999-01-0519.

[54] R. Payri, J. Gimeno, J. P. Viera, A. H. Plazas, Schlieren visualization of transient vapor penetration and spreading angle of a prototype diesel direct-acting piezoelectric injector, in: ICLASS 2012, 1-8, 2012.

[55] R. Payri, J. Gimeno, G. Bracho, D. Vaquerizo, Study of liquid and vapor phase behavior on Diesel sprays for heavy duty engine nozzles, Applied Thermal Engineering 107 (2016) 365-378, doi: bibinfo\{doi\}\{10.1016/j.applthermaleng.2016.06.159\}, URL http://dx.doi.org/10.1016/j. applthermaleng.2016.06.159http: //linkinghub.elsevier.com/retrieve/pii/S1359431116310730.

[56] Z.-Y. Sun, G.-X. Li, C. Chen, Y.-S. Yu, G.-X. Gao, Numerical investigation on effects of nozzle's geometric parameters on the flow and the cavitation characteristics within injector's nozzle for a high-pressure common-rail DI diesel engine, Energy Conversion and Management 89 (2015) 843-861, ISSN 01968904, doi:\bibinfo\{doi\} $\{10.1016 /$ j.enconman.2014.10.047\}, URL http://www. sciencedirect . com/science/article/pii/S0196890414009285.

[57] S. Kook, L. M. Pickett, Liquid length and vapor penetration of conventional, Fischer Tropsch, coal-derived, and surrogate fuel sprays at high-temperature and high-pressure ambient conditions, Fuel 93 (2012) 539-548, ISSN 0016-2361, doi:\bibinfo\{doi\}\{10.1016/j.fuel.2011. 10.004\}, URL http://dx.doi.org/10.1016/j.fuel.2011.10.004.

[58] F. Boudy, P. Seers, Impact of physical properties of biodiesel on the injection process in a common-rail direct injection system, Energy 
Conversion and Management 50 (12) (2009) 2905-2912, ISSN 01968904, doi: \bibinfo\{doi\}\{http://dx.doi.org/10.1016/j.enconman.2009.07.005\}, URL http://www.sciencedirect.com/science/article/pii/ S0196890409002763.

[59] E. Delacourt, B. Desmet, B. Besson, Characterisation of very high pressure Diesel sprays using digital imaging techniques, Fuel 84 (7-8) (2005) 859-867, doi: \bibinfo\{doi\}\{10.1016/j.fuel.2004.12. 003\}, URL http://www.sciencedirect.com/science/article/pii/ S0016236105000062.

[60] B. Mohan, W. Yang, K. L. Tay, W. Yu, Macroscopic spray characterization under high ambient density conditions, EXPERIMENTAL THERMAL AND FLUID SCIENCE 59 (2014) 109-117, ISSN 0894-1777, doi: $\backslash$ bibinfo\{doi\}\{10.1016/j.expthermflusci.2014.08.003\}, URL http://dx . doi .org/10.1016/j.expthermflusci.2014.08.003.

[61] D. L. Siebers, Scaling liquid-phase fuel penetration in diesel sprays based on mixing-limited vaporization, SAE Technical Paper 1999-010528 ISSN 0148-7191, doi:\bibinfo\{doi\}\{10.4271/1999-01-0528\}, URL http://subscriptions. sae.org/content/1999-01-0528/.

[62] M. A. Reddemann, F. Mathieu, D. Martin, R. Kneer, The Influence of Fuel Properties on Spray Propagation , Atomization and Evaporation, in: ILASS 2010, September, 1-6, 2010.

[63] J. Benajes, F. J. Salvador, M. Carreres, D. Jaramillo, On the relation between the external structure and the internal characteristics in the near-nozzle field of diesel sprays, Proceedings of the Institution of Mechanical Engineers, Part D: Journal of Automobile Engineering doi: \bibinfo\{doi\}\{10.1177/0954407016639464\}.

[64] J. Johnson, H.-W. Ge, J. Naber, S.-y. Lee, E. Kurtz, N. Robarge, Investigation of Key Mechanisms for Liquid Length Fluctuations in Transient Vaporizing Diesel Sprays, SAE Technical Paper 2013-01-1594 (2013) 1202-1212ISSN 19463936, doi: \bibinfo\{doi\}\{10.4271/2013-01-1594\}.

Published as: Raul Payri, Juan P. Viera, Venkatesh Gopalakrishnan, Patrick G. Szymkowicz

Fuel (2017), pp. 645-660, DOI information: 10.1016/j.fuel.2016.10.064 